\title{
Los indigenas de la isla Nutka, los otomís, los antiguos mexicanos y las ruinas de San Juan de los Llanos (hoy Cantona) en la Gazeta de Literatura de 1790
}

FIGURAS REVISTA ACADÉMICA DE INVESTIGACIÓN,

ISSN 2683-2917

Vol. 1, núm. 2, marzo-junio 2020

https://doi.org/10.22201/

fesa.figuras.2020.1.2

Recibido:

29 de noviembre de 2019

Revisado:

9 de diciembre de 2019 Aceptado:

22 de enero de 2020

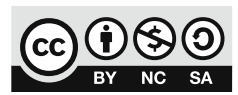

Esta obra está bajo una Licencia Creative Commons AtribuciónNoComercial-Compartirlgual 4.0 Internacional.

Imagen superior: Vista de los habitantes en el archipiélago del Nutka. En: "A Collection of Voyages around te World... Captain Cook's First, Second, Third and Last Voyages...," volumen v, Londres, 1790, página 1767 .

\section{The Nootka Indigenous peoples, Otomís, Ancient Mexicans and the ruins of San Juan de los Llanos (currently Cantona) on the 1790 Gazeta de Literatura}

https://doi.org/10.22201/fesa.figuras.2020.1.2.104

(D) José Humberto Medina González

Empresa Museográfica: Quadrante Plástico

Resumen: En el impreso de la Gazeta de Literatura que salió el día 8 de febrero de 1790 en la capital novohispana, su editor el erudito Antonio Alzate y Ramírez publicó un esbozo de sus primeros estudios sobre los nexos culturales que él encontró entre los nativos del archipiélago del Nutka (hoy en el oeste de Canadá), los otomís, los antiguos mexicanos y su ancestral lugar de origen, a la que agregó una transcripción completa de una noticia escrita en 1786 que le envió el Lic. Ruiz Cañete sobre de una antigua población en San Juan de los Llanos cuyas ruinas localizadas en el estado de Puebla hoy llevan la denominación de Cantona (quizá el registro documental más temprano de esa zona arqueológica a la fecha conocido). Estas ruinas unos años después fueron también visitadas por el arqueólogo-viajero luxemburgués Guillermo Dupaix gracias a la lectura de ese impreso, el que durante varias décadas del siglo xx algunos arqueólogos lo consideraron extraviado o bien dudaron de su existencia. Al final de este artículo como un anexo se ofrece una nueva publicación del impreso. ¿Cuáles fueron las razones para que Alzate publicara en esa fecha ese impreso en su gaceta? 
Palabras clave: Antonio Alzate, Guillermo Dupaix, Joseph Francisco Ruiz Cañete, San Juan de los Llanos, Cantona, Nutka, otomís, antiguos mexicanos, Laguna de Tehuallo, Casa Grande, comparatismo etnográfico, Gazeta de Literatura, conocimiento anticuario y geopolítica.

Abstract: The erudite scholar and editor Antonio Alzate y Ramírez published in his La Gazeta de Literatura (8 February 1790, capital of New Spain) his first study about the cultural connections he discovered between the natives of Nootka Archipielago (today West Canada), the ancient Mexicans, the Otomis and the distant place of their origin. Alzate added to this publication a complete transcription of an early report written by Licenciado Ruiz Cañete in 1786 of an ancient settlement in San Juan de los Llanos, which ruins are located in the State of Puebla, today known as Cantona (probably the earliest documental record of this archaeological zone). A few years later Luxembourgian traveller and archaeologist Guillermo Dupaix visited this sight because he had read Alzate's text. An appendix to this article includes a complete transcription of the report on the ruins of San Juan de Los Llanos, published by Alzate in this Gazeta, which was considered lost by some archaeologists for several decades in the $20^{\text {th }}$ century or its very existence was doubted. Why did Alzate publish this text at this particular date in his Gazeta?

Keywords: Alzate, Dupaix, Ruiz Cañete, San Juan de los Llanos, Cantona, Nootka, Otomís, Ancient Mexicans, Tehuallo Lagoon, Casas Grandes, ethnographic comparatism, Gazeta de Literatura, antiquarian kowledge and geopolitics. 
Al gran mayista Carlos Navarrete por su enorme aportación a la narrativa sobre la historia de la arqueología de finales del siglo XVIII

“... el que sólo arqueología sabe, ni eso sabe”

FRANS BLOM (Navarrete 1991, 31)

\section{Las noticias de 1785, 1791 y 1790 de El Tajín, Xochicalco y San Juan de los Llanos en las gacetas novohispanas}

Desde los comienzos del siglo XIX a la fecha, varios renombrados investigadores mexicanos y extranjeros interesados en el estudio de las antigüedades mexicanas y los ancestrales monumentos de los indígenas, en la historia de la arqueología y el desarrollo de la ciencia en la época Colonial, citaron o transcribieron en sus obras publicadas dos tempranos textos sobre el hallazgo e inspecciones de reconocimiento en las antiguas ruinas de Tajín ${ }^{1}$ y Xochicalco ${ }^{2}$ en las jurisdicciones de Papantla y Cuernavaca, los que respectivamente se imprimieron a mediados de la octava y principios de la novena década del siglo XVIII en la Gazeta de México ${ }^{3}$

1 Humboldt, Ensayo político sobre el Reino de la Nueva España, 178; Márquez, Due antichi monumenti di archittetura messicana, 4-14; Paso y Troncoso, "Dos Monumentos de la Arquitectura Mexicana, Ilustrados por el P. Pedro José Márquez," 280-281; Bernal, "Cien años de arqueología mexicana (1780-1880)," 138-139; Bernal, Historia de la arqueología en México, 73-74; Alcina Franch, "Guillermo Dupaix y los viajes de exploración arqueológica por la Nueva España," 271; Alcina Franch, Arqueólogos o Anticuarios, Historia de la arqueología en la América Española, 114; Pascual Soto, El Tajín en busca de la civilización, 27; López Luján, "El Tajín en el siglo XVIII: Dos exploraciones pioneras en Veracruz," 76; Cabello Carro, "La Arqueología Ilustrada en el Nuevo Mundo," 268-269.

2 Humboldt, Ensayo político sobre el Reino de la Nueva España, 126; Paso y Troncoso, "Dos Monumentos de la Arquitectura Mexicana, Ilustrados por el P. Pedro José Márquez," 281; Márquez, Due antichi monumenti di archittetura messicana, 14-29; Márquez, "Monumentos de arquitectura mexicana ilustrados por el P. Pedro José Márquez," 77-86; Bernal, "Cien años de arqueología mexicana (1780-1880)," 139; Bernal, Historia de la arqueología en México, 73; Litvak, "Investigaciones en el Valle de Xochicalco: 1569-1870," 102-104; Hirth y Cyphers, Tiempo y Asentamiento en Xochicalco, 23; Hirth editor, Archaeological Research. Ancient Urbanism at Xochicalco: The Evolution and Organization of Prehispanic Society, 33-34; Alcina Franch, "Guillermo Dupaix y los orígenes de la arqueología en México," 271-275; Alcina Franch, "Guillermo Dupaix y los viajes de exploración arqueológica por la Nueva España," 222; Alcina Franch, Arqueólogos o Anticuarios, Historia de la arqueología en la América Española, 113-114; Moreno de los Arcos, "Un eclesiástico frente al estado Borbón," 21; Moreno de los Arcos, "Efemérides de José Antonio Alzate y Ramírez," 43; Cabello Carro, "La Arqueología Ilustrada en el Nuevo Mundo," 267-268.

3 Gazeta de Literatura de México núm. 42 del martes 12 de julio de 1785, 349-351. 


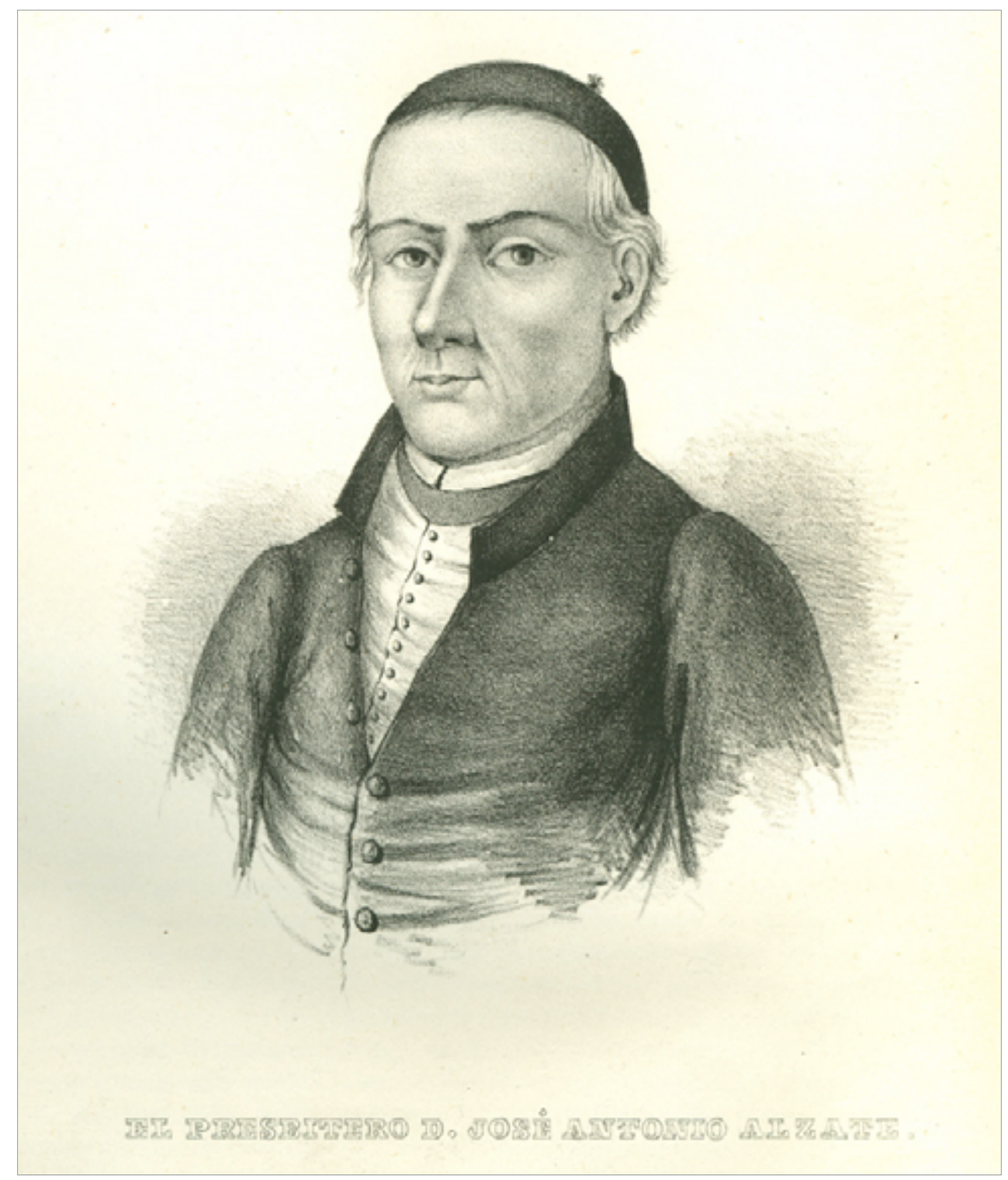

Litografía (L.R., 1843:

El Museo Mexicano, tomo I, 8-9). Digitalización: J.H. Medina González.

a cargo de Manuel Valdés y en la afamada Gazeta de Literatura ${ }^{4}$ del bachiller en Artes y Teología José Antonio Alzate y Ramírez (1737-1799), misma que comenzó a circular en la capital del virreinato desde el 15 de enero de $1788 .{ }^{5}$ Un tercero de estos textos que fue redactado y publicado por el último personaje también en su Gazeta de Literatura y que salió antes del segundo, presenta un esbozo de sus incipientes estudios sobre la isla del Nutka (hoy en Canadá) y de sus habitantes indígenas, de los otomís, así como de la procedencia de los antiguos mexicanos,

4 Ver Alzate, "Descripción de Antigüedades de Xochicalco. Dedicada a los Señores de la Actual Expedición Marítima Alrededor del Orbe," 1791, 1-24.

5 Moreno de los Arcos, "Efemérides de José Antonio Alzate y Ramírez," 43. 
en el que también incluyó una noticia que le escribió el 17 de octubre de 1786 el licenciado en Jurisprudencia Joseph Francisco Ruiz Cañete, comunicándole sobre las ruinas de una antiquísima población que se encontraba dentro de la Jurisdicción de San Juan de los Llanos - cuya cabecera era el poblado del mismo nombre (hoy ciudad Libres) -, inmenso territorio que en la época colonial ocupaba la actual área de la parte norte-centro y noreste del estado de Puebla. ${ }^{6}$ Mientras que el esbozo ha sido transcrito y estudiado principalmente por dos historiadores ${ }^{7}$ con el fin de contextualizar las razones históricas que llevaron al bachiller a su redacción, la noticia que él incluyó sobre los restos arqueológicos de esa antigua población de San Juan de los Llanos -que no es otra que la urbe prehispánica del Cantón, hoy conocida como zona arqueológica de Cantona en Puebla- prácticamente quedó casi borrada de la memoria documental de la arqueología. El poco recuerdo que aún quedó de esa noticia, gracias a su muy escueta referencia bibliográfica -como se expondrá más abajo- que aparece en un artículo editado en los primeros años de la segunda década del siglo anterior por el también casi olvidado arqueólogo Enrique Juan Palacios, incluso recibió reservas por parte de algunos arqueólogos que realizaron exploraciones y la consolidación de sus monumentos arquitectónicos mayores durante varias temporadas en el Proyecto Especial Cantona 1992-1994 del INAH, ${ }^{8}$ quienes señalaron que esa breve referencia brindada en la anterior publicación "... no ha sido corroborada a pesar de los esfuerzos de Tschohl y Nickel". 9 Sin embargo, esos arqueólogos tampoco invirtieron tiempo ni energías en el rastreo de esa noticia en los fondos reservados de las bibliotecas mexicanas. Durante los años 60 del siglo xx, los dos investigadores alemanes antes referidos que participaron en el Proyecto Puebla-Tlaxcala de la Fundación Alemana para la Investigación Científica y Círculo México, se dieron a la tarea de realizar una intensa búsqueda de esa noticia en las bibliotecas de nuestro país y del extranjero; su cuidadoso rastreo bibliográfico en esos acervos y en la literatura de la región hasta ese entonces publicada, aunque no logró cumplir sus expectativas de volverla a encontrar físicamente, sí pudo precisar gracias a la consulta de la obra de Palacios y la información sobre el sitio arqueológico de San Juan de los Llanos que aparece en el apartado del estado de Puebla en el Atlas Arqueológico de la República Mexicana formado por el INAH -y publicado en 1939 por el Instituto Panamericano de Geografía e Historia (en adelante IPGH)-, que dicha noticia efectivamente

6 Gerhard, Geografía histórica de la Nueva España, 1519-1821, 234-235.

7 Carreño, "El bachiller don José Mariano Mociño y la expedición científica del s. XVIII," 18-34.

8 García Cook y Merino, "Cantona: Urbe prehispánica en el Altiplano Central de México," 193-194.

9 García Cook y Merino, "El proyecto arqueológico Cantona," 12. 
se imprimió en la Gazeta de Literatura de Alzate, de ahí que "... debe comenzarse la búsqueda en la segunda serie del tomo I y en el principio del tomo II"10 para así localizar dentro de estos dos ejemplares, el número y mes del impreso donde originalmente se publicó. Gracias a esa pista brindada por los anteriores investigadores alemanes en su Catálogo arqueológico y etnohistórico de Puebla-Tlaxcala editado en 1972, entre septiembre y octubre de 1997, realicé la búsqueda de esta noticia en los impresos originales de la Gazeta de la Literatura del siglo XVIII, cuyos tres tomos empastados custodia la Biblioteca Nacional de México de la UNAM. Durante varios días y después de revisar mes por mes cada una de las gacetas impresas que estaban encuadernadas en el primer tomo, se pudo localizar en este diario de la capital, la tan buscada noticia de la antiquísima población de San Juan de los Llanos, o mejor dicho de las ruinas arqueológicas de Cantona, cuyo último arqueólogo en consultarla y dejar constancia de ella en sus publicaciones y en la información que proporcionó para el Atlas Arqueológico de la República Mexicana, fue el ya referido Enrique Juan Palacios, quizá el último representante de la tradición históricaarqueológica emanada de los sabios decimonónicos del Museo Nacional de México y uno de los autores que publicó de las más grandes narrativas de la historia de la arqueología mexicana que cubre desde la época Colonial hasta la segunda década del s. $\mathrm{Xx},{ }^{11}$ misma que sólo recientemente ha vuelto a ser revalorada y sacada del olvido por los mismos arqueólogos. ${ }^{12}$

El breve esbozo arriba señalado que escribió Alzate sobre los nutkenses y su isla, de la procedencia de los indios mexicanos y la noticia que agregó del estudioso poblano sobre las anteriores ruinas, aparecieron como un artículo en su Gazeta de Literatura en el impreso número 11, páginas 81-84, que salió publicado el 8 de febrero de 1790 en la Ciudad de México. Dicho artículo ${ }^{13}$ titulado Sobre el origen de los mexicanos se reimprimió en el tomo I de los cuatro que integran Las Gacetas de Literatura. Por José Antonio Alzate que en el año de 1831, Manuel Buen Abad publicó en Puebla y también lo editó en 1840 las Memorias de la Sociedad Patriótica de la Habana, Cuba. ${ }^{14}$ Los cuatro tomos antes indicados fueron reeditados en 1893 y 1897-1898 por la Secretaría de Fomento y en 1980 el historiador Roberto Moreno de los Arcos hizo una nueva publicación de las Obras Completas de Alzate en la UNAM de los que sólo se editó el

10 Tschohl y Nickel, Catálogo arqueológico y etnohistórico de Puebla-Tlaxcala, 340.

11 Palacios, "Los Estudios Histórico-Arqueológicos, de México. Su desarrollo a través de cuatro siglos," 95-196.

12 López Hernández, Los estudios histórico-arqueológicos de Enrique Juan Palacios, 11-15.

13 Véase el anexo con la transcripción íntegra de su texto al final del artículo.

14 Alzate, "Sobre el origen de los mexicanos," 1840 [1790], 326-329. 
primer tomo. Se debe señalar que el artículo antes mencionado, ${ }^{15}$ también se volvió a imprimir en 2012 dentro de un volumen con una selección de textos de Alzate que apareció dentro de la colección Cien de México del conACULTA, cuya transcripción cuidadosa del impreso original de la gaceta estuvo a cargo de Miruna Achim, quien además realizó el laborioso trabajo de compilación, notas y edición de esta obra. ${ }^{16}$ La compiladora en su introducción no escribió ningún comentario específico sobre dicho artículo.

\section{La Gazeta de Literatura publicada el 8 de febrero de 1790}

La primera cita del impreso de la Gazeta de Literatura donde apareció la ya referida y breve noticia escrita de Juan R. Cañete sobre el antiquísimo poblado de San Juan de los Llanos - posteriormente denominado del Cantón y hoy zona arqueológica de Cantona-, la escribió el mismo José Antonio Alzate y Ramírez en el Suplemento para la "Descripción de Antiguedades de Xochicalco. Dedicada a los Señores de la Actual Expedición Marítima Alrededor del Orbe", que apareció en el año de 1791 en el tomo II de su Gazeta de Literatura, ${ }^{17}$ en la que ofreció una narrativa producto de las inspecciones realizadas en los años de 1777 y 1784 al cerro fortificado de Xochicalco cercano a Cuernavaca. Al comienzo de dicho suplemento señaló:

... en la Gaceta de Literatura número 11 traté de su origen [de los mexicanos], y a mi juicio confirmé con sólidos fundamentos la opinión de algunos historiadores que piensan que vinieron de la laguna de Tehuallo; en otras, siempre que el asunto me lo ha permitido, he procurado esparcir algunas reflexiones capaces, a mi juicio, de persuadir que la nación mexicana no era tan poco culta como se cree comúnmente. ${ }^{18}$

15 Alzate, "Sobre el origen de los mexicanos," 2012 [1790], 410-414.

16 Alzate, Observaciones útiles para el futuro de México.

17 Alzate, "Descripción de Antigüedades de Xochicalco. Dedicada a los Señores de la Actual Expedición Marítima Alrededor del Orbe," 1791, 1-24; Alzate, "Descripción de Antigüedades de Xochicalco. Dedicada a los Señores de la Actual Expedición Marítima Alrededor del Orbe," 1831 [1791], 1-16; Alzate, "Descripción de antigüedades de Xochicalco. Dedicada a los señores de la actual expedición marítima alrededor del orbe," 2012 [1791], 415-448.

18 Alzate, "Señores", sin paginación en "Descripción de Antigüedades de Xochicalco. Dedicada a los Señores de la Actual Expedición Marítima Alrededor del Orbe," 1791; Alzate, "Descripción de antigüedades de Xochicalco. Dedicada a los señores de la actual expedición marítima alrededor del orbe," 2012, 416. 
En el párrafo anterior, al haber hecho mención Alzate del número 11 de su Gazeta de la Literatura donde trató la cuestión sobre los indios del Nootka o Nutka, así como el lugar de salida y mansiones de la antigua nación indígena mexicana desde el lejano Norte, no hay la menor duda de que él claramente hizo referencia al impreso de la misma correspondiente al 8 de febrero de 1790 , el que inicia con una nota suya titulada "Sobre el origen de los indios mexicanos", a cuya continuación le añadió la ya señalada noticia del 17 de octubre de 1783 sobre las ruinas de la antigua población en la comarca de San Juan de los Llanos que le envió el Lic. Cañete.

\section{Sobre el origen de los indios mexicanos}

La sección referente a la nota de Alzate que trata sobre los indígenas de Nutka, los otomís y mexicanos, los indicios de ciertas relaciones culturales entre los tres y con la historia más antigua del lugar de origen de los últimos en la incógnita América Septentrional y sin la noticia de las antiquísimas ruinas de San Juan de los Llanos, el historiador Alberto Mariano Carreño la transcribió -exceptuando su primer párrafo- en su estudio introductorio sobre "El Bachiller Don José Mariano Moziño y la Expedición Científica Méxicana del s. XVIII", que precede a la publicación mexicana de las Noticias del Nutka y un ensayo sobre el Diccionario de la Lengua de los Nutkenses del mismo Moziño, que la Secretaría de Fomento editó en 1913.

Es importante señalar que Carreño atribuyó el texto de la nota al Sr. Cañete y no al ilustrado novohispano que claramente la redactó para su gaceta. De igual manera, esa misma sección con sus respectivas notas a pie y también sin la noticia de las ruinas, el historiador Felipe Echenique March, la publicó en 2013 dentro de un "Ensayo" que preparó para el libro José Mariano Moziño y sus Noticias del Nutka, a través del

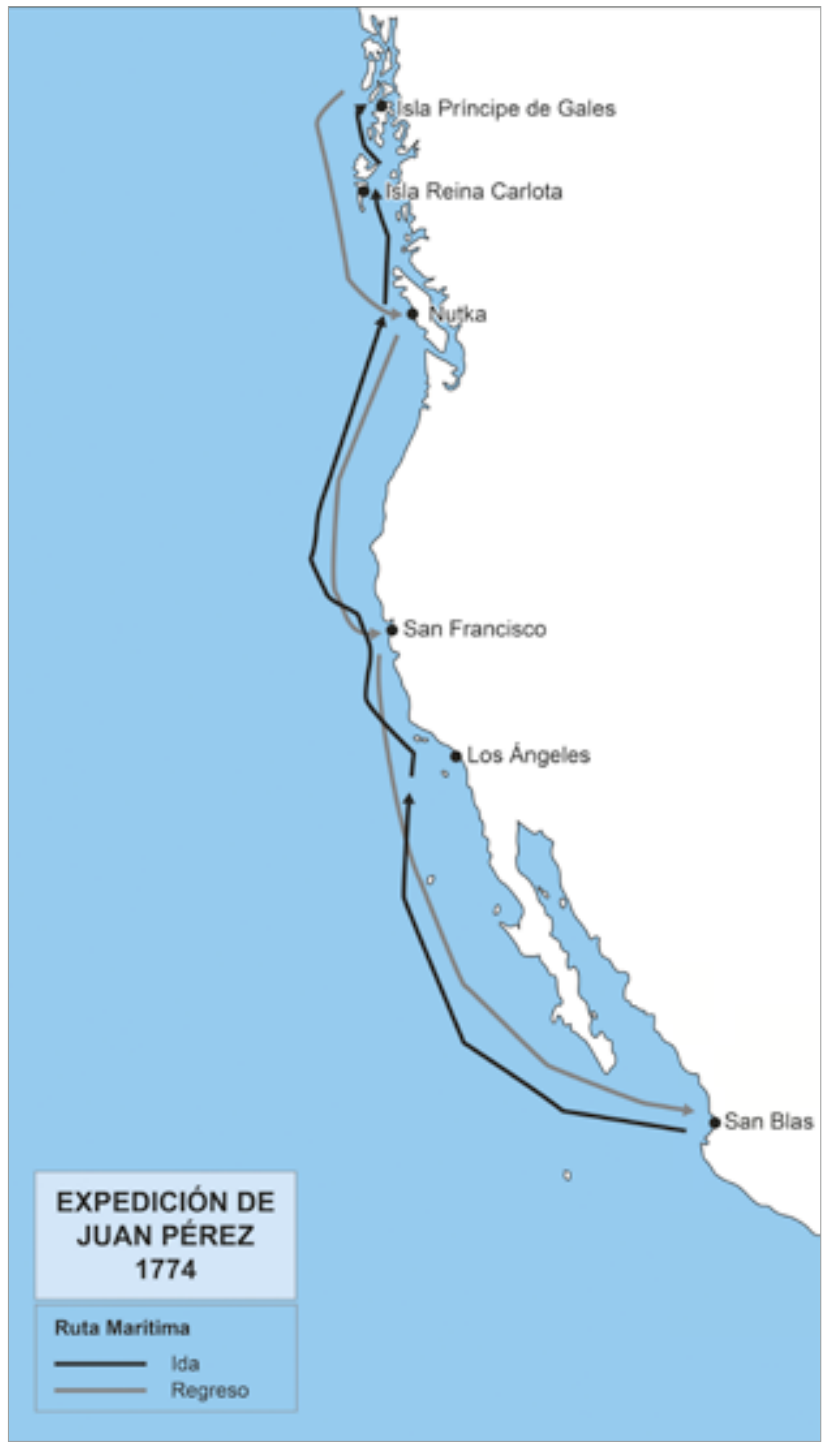

Mapa de la ruta de José Juan Pérez Hernández desde San Blas al Nutka y regreso (http://www.momentosespañoles.es/contenido. php?recordID=535), redibujado por Guadalupe Martínez. 
tiempo ${ }_{19}^{19}$ con el fin de exponer el contexto histórico que rodeaba al bachiller cuando la redactó y editó en su gaceta. Lo que resulta asombroso de dicha nota es que de manera repentina y sin ningún antecedente en su obra publicada, el presbítero escribiera sobre la población nativa que habitaba en los territorios de lo que entonces eran los confines más septentrionales de la Nueva España y de la Alta California, de esa muy lejana región en la costa noroccidental del Pacífico, que por esa época comenzaba a denominarse el puerto de San Lorenzo de Nutka en la llamada isla de Mazarredo (hoy localizada en la costa oriental de la isla de Vancouver en la Columbia Británica al oeste de Canadá). Esa isla apenas descubierta en el año de 1774 por el piloto español Juan Pérez, “... no comenzó a tener celebridad hasta el de 1778, en que el infatigable Santiago Cook [o capitán Cook] la reconoció, y halló en ella abundante peletería, cuyo comercio presumió justamente que sería ventajoso a su nación". ${ }^{20}$ La riqueza natural que había en esta porción territorial, la más septentrional e incógnita tanto de la Nueva España como de la Alta California, generó una disputa entre las monarquías de España e Inglaterra por su posesión y dominio territorial, aunado al hecho de que en sus alrededores se habían establecido otros asentamientos rusos también dedicados a la explotación y comercio de pieles. Pero lo que es aún más sorprendente en esa nota, como también ya lo señalaron los dos anteriores historiadores, fue el esfuerzo de Alzate por tratar de establecer vínculos históricos y, los que podríamos hoy denominar, paralelos o acercamientos etnográficos entre esos lejanos nativos de la Costa Noroeste del Pacífico con los pueblos indígenas otomís y mexicanos del centro de México, a través de la tradición escrita sobre la partida de los ancestros de los últimos desde el septentrión, apoyada por lo que aseguran ciertos historiadores y los restos de sus mansiones que dejaron allá durante su trayecto al centro de la Nueva España, y también por la semejanza de ciertas manifestaciones culturales (vestimenta, escritura y lenguaje) aparentemente compartidas por los dos pueblos antes indicados y los distantes indios del Nutka o Nootka. La información sobre los hábitos, costumbres y algunas palabras de la lengua de los últimos, Alzate indicó que los registró del libro de los viajes del capitán Cook $^{21}$ específicamente del Diario del tercer viaje del

19 Echenique March, Noticias de Nutka a través del tiempo, 275.

20 Moziño, "Noticias del Nutka," 149.

21 Echenique March, “Ensayo. José Alzate y Ramírez, impulsor intelectual de José Mariano Moziño y sus noticias del puerto de San Lorenzo de Nutka en la Nueva California," 20. 
capitán Cook cuya primera publicación apareció en Londres, Inglaterra en $1784^{22}$ y fue tal su éxito que exceptuando en España, en los años siguientes aparecieron en otros países europeos, otras impresiones de esta obra en sus idiomas respectivos. El historiador Echenique sospecha que el Diario del tercer viaje del capitán Cook que Alzate consultó cuando escribió esta nota para la gaceta, al no encontrarse en las bibliotecas de la Nueva España, era un ejemplar que traían los capitanes ingleses James Colnett y Thomas Hudson, quienes en los primeros meses de 1790 estuvieron presos en la Ciudad de México. Las razones de su estancia aquí se deben a que a la mitad del año anterior arribaron con sus embarcaciones el paquebote Argonauta y la balandra Princesa Real al puerto de San Lorenzo de Nutka, con el objeto de fundar un establecimiento para el comercio de pieles de nutria y así comenzar a adueñarse de esos territorios. Después de un enfrentamiento con el alférez del navío español Esteban José Martínez que había llegado antes a tomar posesión formal de dicho puerto en nombre del Rey de España, Carlos III; ambos capitanes fueron capturados por él y sus embarcaciones con tripulaciones y cargamentos fueron decomisados y transportados al sur hacia el Puerto de San Blas, hoy en las costas de Nayarit. Ahí estuvieron presos los ingleses los meses restantes y a principios de 1790 y con la autorización del virrey Juan Vicente de Güemes Pacheco de Padilla y Horcasitas, segundo Conde de Revillagigedo (quien asumió su cargo en octubre de 1789), los dos capitanes pasaron a la capital del virreinato para defender ante la Audiencia de México los intereses de posesión de Inglaterra sobre el archipiélago del Nutka. Fue en el juicio sumario - según lo especulado por el Dr. Echenique-, cuando los ingleses no sólo exhibieron el Diario de Cook como un documento donde estaban asentados los derechos territoriales de su corona sobre ese lugar, sino también durante el desarrollo de este proceso fue cuando Alzate quizá tuvo acceso a esa publicación, la que llegó a conocer muy bien en su texto y las láminas dibujadas que la acompañan como se aprecia en su nota. La interesante especulación del Dr. Echenique ofrece ciertas razones que le dan fuerza de credibilidad a falta de testimonios escritos:

... quizá por ahora también debamos figurarnos que la Audiencia recurrió a Alzate para que diera alguna opinión sobre el Diario del capitán Cook, toda vez que

22 Para ese viaje, véase la publicación de Anderson (editor), A New, authentic, and complete collection of voyages round the world, undertaken and performed by royal authority: containing an authentic, entertaining, full, and complete history of Captain Cook's first, second, third and last voyages, undertaken by order of his present Majesty, for making discoveries in geography, navigation, astronomy, \&c. in the southern and northern hemispheres \&c. \&c. \&c.... the whole comprehending a full account, from the earliest period to the present time/now publishing under the immediate direction of George William Anderson, Esq.; assisted by a principal officer who sailed in the Resolution sloop, and by many other gentlemen of the most distinguished naval abilities, 399-655 
la edición presentada no estaba traducida al castellano y que tenía que ver con las materias que dominaba el editor de la Gaceta de la Literatura, a quien, no está por demás recordarlo, en otros casos recurrieron los virreyes para conocer su punto de vista. Hasta el momento no puedo afirmar que la Audiencia o el virrey hayan solicitado la opinión de Alzate en este caso particular. Pero, a menos que haya ocurrido otra circunstancia como la de tratar directamente con los capitanes ingleses detenidos en la ciudad de México, no encuentro como Alzate habría tenido acceso a este diario...23

Mientras los anteriores hechos ocurrían en la capital de Nueva España, el 7 de febrero de 1790, el virrey Revillagigedo instruyó que la fragata la Concepción, el paquebote Argonauta y la balandra Princesa bajo el mando del teniente de navío Francisco Eliza y los oficiales Salvador Hidalgo y Manuel Quimpera, alzaran las velas en el puerto de San Blas con ruta hacia el puerto del Nutka. El objetivo era ocupar nuevamente el archipiélago que después del enfrentamiento y captura de los capitanes y la flota inglesa por el ya referido Esteban Martínez, quien había recibido órdenes por parte del virrey anterior Manuel Antonio Flores de abandonarlo. Con esos eventos de la capital y lo que sucedía en el puerto en la fecha antes indicada, se puede dar cuenta la razón por la que al día siguiente (el 8 de febrero) se publicó en el número 11 de la Gazeta de Literatura, el "Origen de los mexicanos".

En su nota Alzate escribió sobre las ya referidas semejanzas en la vestimenta, el peinado, la glífica esculpida sobre ciertos elementos arquitectónicos -como los pilastrones con relieve que consultó en la lámina titulada The Inside of a House in Nootka Sound (trad. El Interior de la Casa en el Estrecho Nutka) publicada en el tercer viaje de Cook- y de algunas palabras de la lengua que los nativos del Nutka comparten con los indios otomís y mexicanos; así como de las particularidades culturales que los diferencian de acuerdo al clima -según se pensaba en esa época-, y también sobre la tradición histórica de la migración de Norte a Sur de los últimos antes de asentarse en el Valle de México. Su intención al escribirla era que, a partir de exponer esas afinidades culturales que él detectó entre esos lejanos pueblos -del oeste de Canadá y del centro de México - y al utilizar la autoridad de los historiadores, de las fuentes históricas y de los restos arqueológicos dejados en Tehuallo, Gila y de Casas Grandes que dan cuenta del lugar de partida y sobre el desplazamiento de los antiguos mexicanos desde el septentrión, no sólo cuestionó la supuesta supremacía que reclamaban los ingleses sobre el descubrimiento del archipiélago del Nutka sino también, como lo hizo en muchas de sus publicaciones, expresó su

23 Echenique March, “Ensayo. José Alzate y Ramírez, impulsor intelectual de José Mariano Moziño y sus noticias del puerto de San Lorenzo de Nutka en la Nueva California," 24. 
"... toma de posición" frente a los hechos que se estaban presentando al preservar los derechos territoriales de la corona española sobre aquel puerto y sus habitantes, “... 'porque primero en tiempo, primero en derecho' según la antigua fórmula jurídica del llamado derecho de gentes, aunque ello nunca lo estableció explícitamente [como] el editor de la Gazeta de Literatura ya que resultaba familiar para las coronas que se disputaban los territorios no ocupados por ellas". ${ }^{24} \mathrm{Y}$ es que esta nota del polígrafo Alzate tenía un destinatario específico como ocurrió con la mayoría de las que redactó como editor y propietario de la anterior publicación. Ese destinatario específico, que a la vez se encontraba próximo y distante, eran los ingleses. Los próximos eran los capitanes Colnett y Ulson que como ya se indicó estaban presos en la Ciudad de México y bajo juicio sumario ante la Audiencia. Los distantes serían las autoridades correspondientes de la isla británica, a quienes los capitanes Colnett y Ulson, una vez que fueran liberados y establecieran de nuevo contacto directo con ellas, les mostrarían esa nota impresa e informarían sobre los eventos acaecidos desde su captura en el puerto del Nutka, su traslado y arribo al puerto de San Blas e igualmente a la capital virreinal y lo que se resolviera de ese proceso legal. ${ }^{25}$
Lámina "El Interior de una Casa en el Estrecho del Nutka" (Anderson [editor] 178, 540-541). Digitalización: J.H. Medina González.

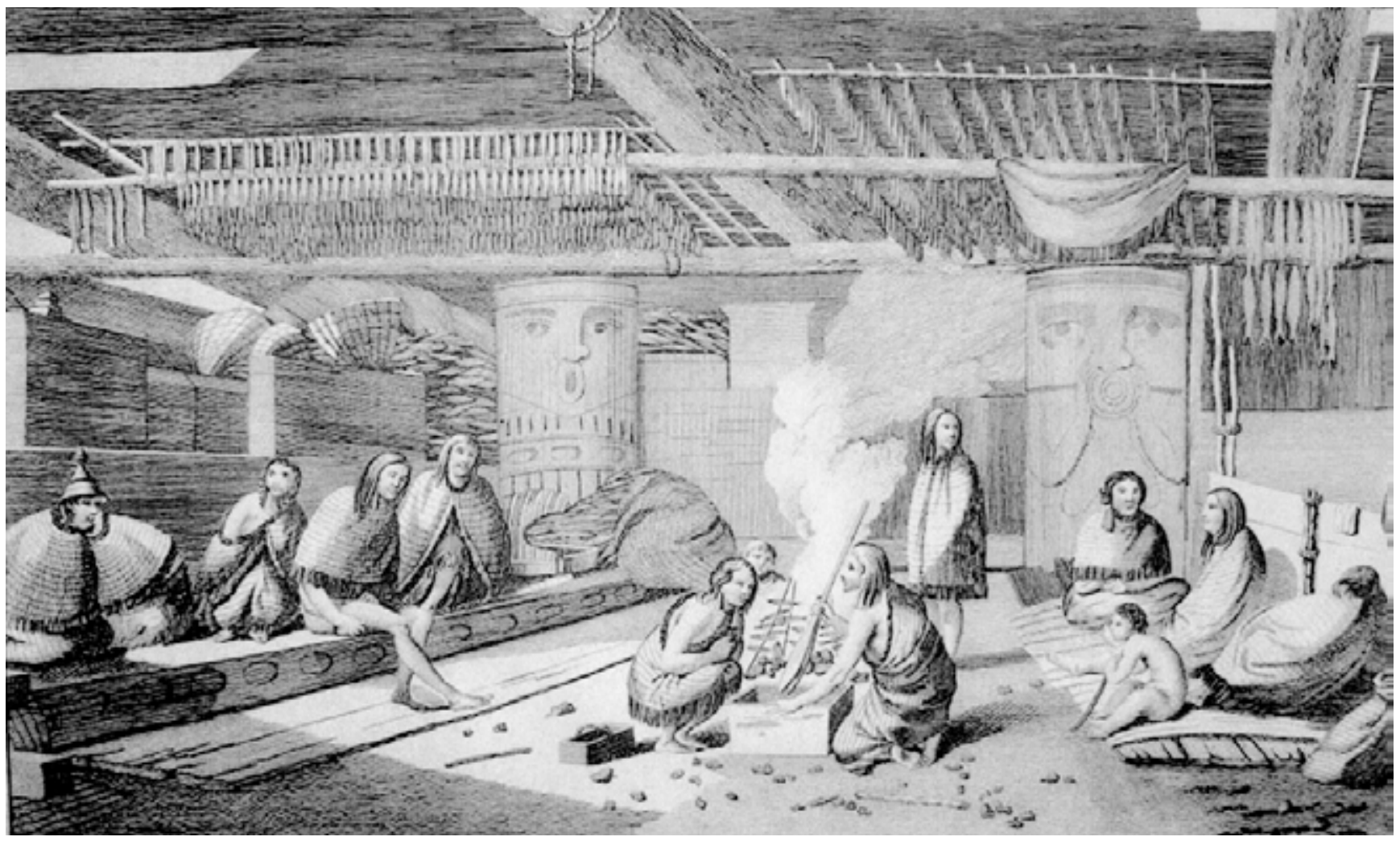

24 Echenique March, "Ensayo. José Alzate y Ramírez, impulsor intelectual de José Mariano Moziño y sus noticias del puerto de San Lorenzo de Nutka en la Nueva California," 29.

25 Ibidem, 25. 
Con respecto a los datos sobre los nativos mexicanos consignados en esta nota, Alzate los consultó en las láminas dibujadas de la Matrícula de Tributos que aparecieron en el libro de Hernán Cortés titulado Historia de la Nueva España que el Arzobispo Lorenzana publicó en $1770 ;{ }^{26}$ y también se refirió a que en el año de 1777, por orden real, se mandaron destruir dos pilastrones tallados con bajorrelieves que se encontraban en la laguna de Texcoco, en el lugar denominado Pantitlán. Mientras que los referentes a los otomís del valle de Toluca y al oeste en Michoacán provienen de sus observaciones de esos últimos y de las proporcionadas por su colaborador en la Gaceta de Literatura, el ya mencionado José Mariano Moziño, ${ }^{27}$ médico y botánico originario de Temascaltepec, hoy en el Estado de México y miembro de la Real Expedición Científica [o Botánica] al Virreinato de la Nueva España (1787-1803), a quien el 21 de diciembre de 1791 se le ordenó incorporarse como naturalista a la Expedición de Límites al Norte de California comandada por el almirante español Juan Francisco de la Bodega y Quadra, cuyas embarcaciones partieron desde el Puerto de San Blas en Nayarit con dirección hacia la costa Noroeste del Pacífico con la orden del virrey el segundo Conde de Revillagigedo, de entrevistarse con el comisionado inglés G. Vancouver para solucionar los alegatos de posesión del archipiélago nutkense entre España e Inglaterra, lo cual sucedió hasta la convención firmada en San Lorenzo del Real en $1793 .{ }^{28}$ Gracias a la lectura que Moziño hizo de la noticia publicada por el erudito novohispano dos años antes, se interesó por conocer mejor esos lejanos y quizá ancestrales vínculos entre las poblaciones indígenas más septentrionales con aquellas del centro de la Nueva España, de ahí que no perdió la oportunidad de aprovechar este largo viaje por la costa Noroeste del continente para recabar más datos etnográficos de los nutkenses y de su lengua, los que dio a conocer a su regreso a México en su ya señaladas Noticias del Nutka, mismas que escribió en el año de $1793 .{ }^{29}$

26 Cortés, Historia de la Nueva España, 1770, 400; Cortés, Historia de la Nueva España, 1981 [1770], tomos I, II, III y IV.

27 Carreño, "El bachiller don José Mariano Mociño y la expedición científica del s. XVIII," 45 y 112; Echenique March, "Ensayo. José Alzate y Ramírez, impulsor intelectual de José Mariano Moziño y sus noticias del puerto de San Lorenzo de Nutka en la Nueva California," 20, nota al pie $n^{\circ} 17$ y bibliografía, 246-247.

28 Lozoya, Plantas y Luces en México, La Real Expedición Científica (1787-1803), 115.

29 Moziño, "Noticias del Nutka," 147-244; Lozoya, op. cit., 111. 


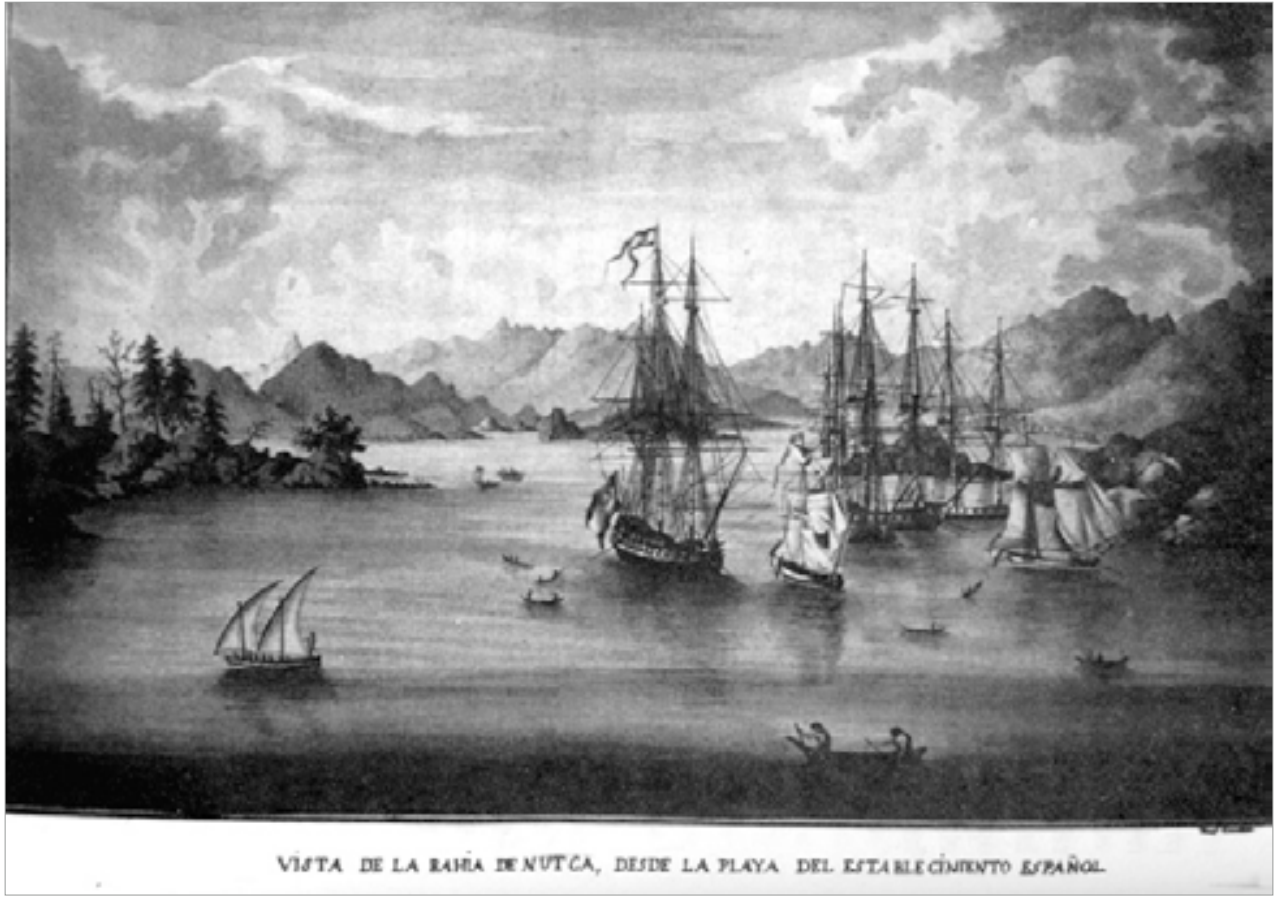

Regresando a las fuentes documentales de las que Alzate obtuvo información para la nota que estamos tratando, referente a los extensos territorios del Septentrión, donde se localizaba la Laguna [o Reino con sus siete cuevas] de Tehuallo [o Teguayo] de la que, con sólido fundamento se decía que de ahí o de sus inmediaciones salieron los antiguos mexicanos o Nación Mexicana ${ }^{30}$ y de las ruinas como Casa Grande en las orillas del Gila (hoy Arizona) y de Casas de Grandes, ${ }^{31}$ en las cercanías del presidio de Janos (en Chihuahua) que eran sus dos otras mansiones dejadas allá en su migración hacia el sur, se apoyó en los planos geográficos de la Nueva España trazados por él y en la lectura de manuscritos sobre la Pimería Alta (hoy Sinaloa, Sonora y Sur de Arizona), y la Nueva Vizcaya que fueron redactados en los siglos XVII y XVIII por jesuitas y militares, asimismo consultó otros libros editados en ese último siglo. Los documentos cartográficos en los que se apoyó para obtener las coordenadas aproximadas de longitud y latitud geográfica para la ubicación de la laguna y de los restos de tres las mansiones antes señaladas y que escribió al pie de página en su nota fueron su Nuevo Mapa Geográfico de la América Septentrional Española, dividida en Obispados y Provincias de 1767, que dedicó a Francisco Antonio
Lámina con una panorámica del Nutka (Moziño, 2013 [1793], 216). Digitalización: J.H. Medina González.

30 Mange, Luz de tierra incógnita en la América Septentrional y Diario de las exploraciones en Sonora, 222.

31 Para las fuentes documentales de los siglos XVI, XVII y XVIII sobre estas ruinas véase Mendiola, Las texturas del pasado. Una historia del pensamiento arqueológico en Chihuahua, 128-164. 
Lorenzana, arzobispo de México. ${ }^{32}$ Igualmente su Plano de la Nueva España en que se señalan los Viages que hizo el Capitan Hernan Cortes assi antes como después de Conquistado el Imperio Mexicano que elaboró en $1769^{33}$ y una copia de un mapa elaborado en 1541 por el Capitán Domingo del Castillo que muestra "... los litorales del Pacífico que señalan a la Península de California no completa, hasta los 47 grados, y en un distante punto del septentrión la ciudad de Cíbola, sin que se pudiera saber qué más hay allá de esos confines", ${ }^{34}$ ambos mapas fueron publicados por Lorenzana en su libro de Hernán Cortés ya arriba citado. ${ }^{35}$ Así como sus planos Geográfico de la mayor parte de la América Septentrional Española firmado y rubricado en México, a 23 de octubre de $1772^{36}$ y de las Provincias de Ostimuri, Sinaloa Sonora, y demás circunvezinas y parte de California, este último también elaborado en $1772 .{ }^{37}$ Mientras que los documentos de los jesuitas y militares en los que también escribieron sobre esas tres mismas mansiones, el polígrafo consultó el manuscrito los Favores Celestiales... ${ }^{38}$ que el misionero Eusebio Francisco Kino redactó entre los años de 1699-1710 -información que se puede corroborar en las glosas que escribió en su último plano de 1772-, quizá la relación del Capitán Juan Matheo Mange que aparece en su obra Luz de Tierra Incognita en la América Septentrional y Diario de las Exploraciones en Sonor ${ }^{39}$ y quien en varias de sus expediciones en este último territorio y sur de Arizona acompañó al anterior y también el Diario de la expedición de 1774 a 1776 en Sonora y la Alta California del teniente y capitán Juan Bautista de Anza Bezerra Nieto, ${ }^{40}$ el que se encontraba en el entonces archivo de la Secretaría del Virreinato y cuya consulta por parte de Alzate se puede constatar gracias a las

32 Museo Naval de Madrid, España, Sala de Investigación.

33 Varilla OYBRM03, no. de clasificador: 1413-OYB-72-A, Mapoteca Orozco y Berra, SAGARPA, Ciudad de México.

34 Echenique March, "Ensayo. José Alzate y Ramírez, impulsor intelectual de José Mariano Moziño y sus noticias del puerto de San Lorenzo de Nutka en la Nueva California," 26.

35 Cortés, Historia de la Nueva España 1770 y Cortés, Historia de la Nueva España, 1981 [1770], tomos I y III.

36 Museo Naval de Madrid, España, número de catálogo VIII-A-9.

37 Mapa de las Provincias de Ostimuri, Sinaloa Sonora, y demás circunvezinas y parte de California, Mapoteca Orozco y Berra, SAGARPA, Varilla OYBBC01, no. de clasificador 266-OYB-7221-A.

38 Kino, Las Misiones de Sonora y Arizona comprendiendo: La crónica titulada: "Favores Celestiales" y la "Relación Diaria de la Entrada al Noroeste," 28-29 y 356.

39 Mange, Luz de tierra incógnita en la América Septentrional y Diario de las exploraciones en Sonora [1720], 252- 253.

40 De Anza, “Anza's Diary of the Second Anza Expedition, 1775-1776 (J)," 196 y 197-199. 


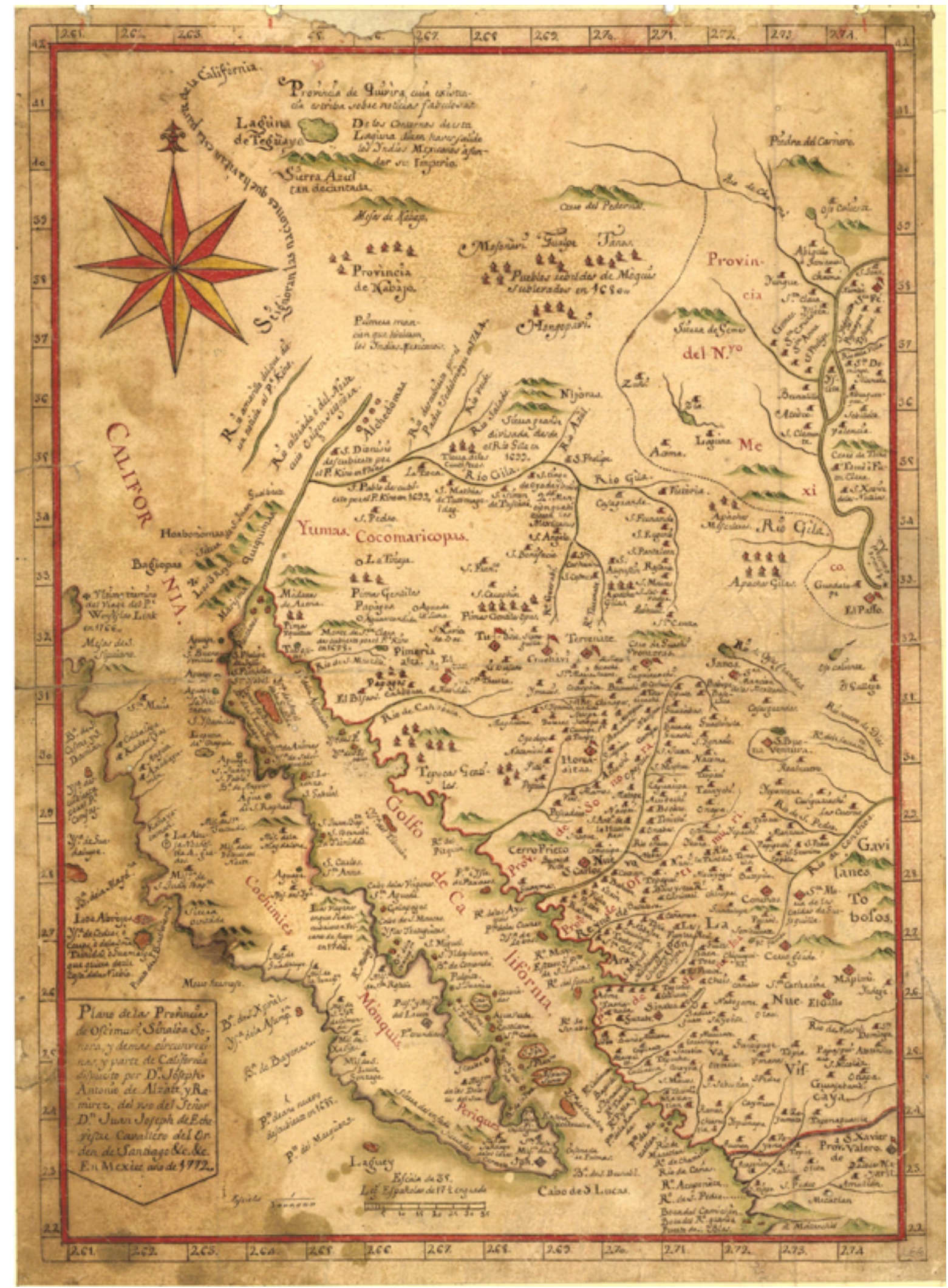

Mapa de las Provincias de Ostimuri, Sinaloa Sonora, y demás circunvezinas y parte de California, elaborado por Alzate en el año 1772. En su parte superior dibujó la Laguna de Tehuayo y al sur las tres primeras mansiones de los antiguos mexicanos que dejaron atrás en su migración (SAGARPA, Mapoteca Orozco y Berra, Varilla OYBBC01, no. de clasificador 266-OYB-7221-A). 
anotaciones que hizo entre los años $1789-1792^{41} \mathrm{y}$ añadiendo otras entre $1795 \mathrm{o}$ $1796^{42}$ a la Historia Antigua de México de Francisco Xavier Clavijero que se imprimió en lengua italiana en 1780 y de la que se esperaba una pronta publicación en español. Con respecto a los libros impresos, no hay la menor duda que leyó la anterior publicación la que según él llegó a la Nueva España en $1784^{43}$ y también consultó el apartado titulado de los Pobladores de la Nueva España incluido en las "Advertencias para las Cartas de Hernán Cortés" que aparecen en el ya señalado libro del Arzobispo Lorenzana. ${ }^{44}$ Gracias a la información proporcionada por los anteriores documentos y obras publicadas, el bachiller en primer término dio cuenta al principio de su noticia de lo ya señalado por la autoridad de ciertos historiadores y por la tradición de algunas naciones indias del Norte (como los pimas), quienes aseguraban que los antiguos mexicanos dejaron los restos de sus mansiones en los alrededores de Tehuallo [o Teguayo], lugar de donde partieron y en los subsecuentes lugares como Casa Grande y Casas Grandes, cuyas ruinas son el testimonio de su paso por los incógnitos territorios septentrionales. De ahí estableció una conexión de esa ancestral historia de migración de los mexicanos, de sus ruinas dejadas en el septentrión y de sus afinidades culturales ya señaladas que guardan no sólo con los otomís sino también con los distantes indios de la isla del Nutka.

El objetivo de Alzate por establecer estas conexiones entre estos tres pueblos indígenas utilizando datos que se podrían denominar histórico-arqueológicos y etnográficos era refutar ese supuesto primer descubrimiento de la mencionada isla por parte de los ingleses. El bachiller, al insinuar que en tiempos muy lejanos y quizá de un mismo lugar de origen, en este caso Tehuallo, los antiguos mexicanos y otomís partieron con dirección al sur para establecerse en lo que después sería el centro de la Nueva España y quizá los ancestros de los indios nutkenses se encaminaron al Norte a los incógnitos territorios más allá de la Alta California, señaló que desde los orígenes hubo un lejano parentesco entre esos tres pueblos cuya manifestación más evidente es que aún compartían varios de los rasgos culturales antes referidos. De ahí que siguiendo esa máxima, “... que reza: 'Lo que es primero en tiempo es primero en derecho'. Los primeros en tiempo y en derecho en aquellos

41 Moreno de los Arcos, "Las Notas de Alzate a la Historia Antigua de Clavijero," 363- 364 y Moreno de los Arcos, "Las Notas de Alzate a la Historia Antigua de Clavijero (Addenda)," 119, véase notas críticas de Alzate a la Historia Antigua de Clavijero, (nota 150), 518.

42 Moreno de los Arcos, "Las Notas de Alzate a la Historia Antigua de Clavijero (Addenda)," 188.

43 Alzate, "Descripción de Antigüedades de Xochicalco. Dedicada a los Señores de la Actual Expedición Marítima Alrededor del Orbe," 1791, 1.

44 Cortés, Historia de la Nueva España, 1770, 4- 5; Cortés, Historia de la Nueva España, 1981 [1770], tomo I, 4-5. 
territorios [del Nutka] eran los mexicanos y los otomíes, justamente los pueblos que le sirvieron a Alzate para refutar el supuesto descubrimiento de los ingleses." 45 La implicación y proyección de lo señalado antes por el anterior en su nota que estamos tratando, se expresaba en la posibilidad de poder ampliar aún más hacia el septentrión el horizonte:

... [de] la extensión territorial que alcanzaría la Nueva España si hundía sus raíces en el pasado prehispánico. Bajo esta línea interpretativa, Alzate se mostraría como un novohispano expansionista que afianzaba su pretensión en los lazos histórico-culturales entre los pueblos de Nutka y los mexicanos y otomíes, estos últimos suponía Alzate, ya integrados al mundo novohispano. ${ }^{46}$

Y es que toda esta argumentación del sabio novohispano apoyada en su manejo y la comparación de datos históricos-arqueológicos y etnográficos de esos tres grupos indígenas tenía entre sus propósitos, lo ya señalado, que era preservar los derechos de la corona española sobre el archipiélago del Nutka y de sus gentes de las otras monarquías -en particular la de Inglaterra- y competidores comerciales europeos que se disputaban estos distantes territorios en la costa noroccidental del Pacífico.

\section{La noticia del señor Cañete sobre las ruinas de San Juan de los Llanos (Cantón o Cantona)}

En el año de 1922, el arqueólogo Enrique Juan Palacios y el ciudadano José Miguel Sarmiento, en ese entonces ambos adscritos al Museo Nacional de Arqueología, Historia y Etnografía de México dependiente del Ministerio de Educación Pública, hicieron una expedición al Cofre de Perote en el estado de Veracruz. Al recorrer una de las faldas de este volcán descubrieron en superficie los restos arquitectónicos y tiestos cerámicos de una urbe prehispánica antes desconocida que los lugareños denominaban Pueblo Viejo y que ellos nombraron "Hueyaltépetl". Una vez terminada dicha inspección y con el fin de obtener información de otras ruinas cercanas que ayudaran a establecer ciertas analogías o formar comparaciones de estudio con las antes descubiertas, ambos investigadores se encaminaron a la llanura de San Juan de los Llanos en el territorio poblano en cuya inmensa planicie se encuentran las amplias coladas de lava, producto de la erupción volcánica de la Caldera de

\footnotetext{
45 Echenique March, op. cit., 31.

46 Ibidem, 33.
} 
los Humeros. ${ }^{47}$ En aquellas que forman el inmenso malpaís que se encuentra dentro de las tierras de la ex hacienda de Xaltipanapa (hoy poblado) y muy cercanas a la población Tepeyahualco (actual cabecera municipal del mismo nombre), visitaron los vestigios de la "gran ciudad de Cantona", denominación que actualmente recibe la zona arqueológica y que el afamado antropólogo físico Nicolás León del Antiguo Museo Nacional de México, otorgó así en un artículo titulado "Los monumentos arqueológicos de Cantona" que salió publicado en 1903 en dos diarios en español e inglés, respectivamente el Semanario Literario Ilustrado ${ }^{48}$ y Records of the Past. ${ }^{49}$

El breve reporte de Palacios sobre esta rápida visita a las anteriores ruinas que terminó en mayo de ese mismo año apareció en dos artículos titulados "Descubrimientos de la ciudad de Hueyaltépetl en los límites de la altiplanicie de México.-por Juan Palacios y Miguel E. Sarmiento del Museo Nacional de Arqueología, Historia y Etnografía" y "Hueyaltépetl", que fueron publicados respectivamente en el Boletín de la SEP y en los Anales del Museo Nacional de Arqueología, Historia y Etnografía. En ambos artículos Palacios escribió que según los datos consignados en las "Gacetas de Alzate" o "Gazetas de Alzate" - refiriéndose claramente a las Gazetas de Literatura de las que no ofreció mayor información sobre el número del ejemplar o año de su publicación y nunca a las de Gacetas México-, aparece “... (la primera e interesante referencia sobre Cantona), sábese de una mesa monolítica en piedra muy dura y fina, la cual estaba pulimentada en forma exquisita: los pies de esa mesa formaban parte del monolito" o bien de dichas ruinas se "dan noticia" en este diario novohispano. ${ }^{50}$ En su noticia el Lic. Cañete así describió esa mesa: "Yo hice sacar una mesa de piedra cuya longitud tenía cerca de dos varas, la latitud cosa de tres quartas, y la profundidad como una tercia: los pies eran quatro, de una pieza con la tabla, y de un palmo de altura. No he visto lápida mas bella." 51

La anterior cita corrobora plenamente que Palacios sí consultó la anterior noticia de la Gaceta de Literatura. De igual manera en el ya referido Atlas Arqueológico de la República Mexicana del año 1939 cuya Carta Arqueológica según el Arquitecto Ignacio

\footnotetext{
47 García García, La plaza oriente de Cantona, Puebla, cultura material y cosmovisión, 16.

48 León, "Los monumentos arqueológicos de Cantona," 248-250.

49 León, Records of the Past, 224; García García, op.cit., 20.

50 Palacios, "Hueyaltépetl,"121, nota al pie* y 122; Palacios, "Descubrimientos de la ciudad de Hueyaltépetl en los límites de la altiplanicie de México. - por Juan Palacios y Miguel E. Sarmiento del Museo Nacional de Arqueología, Historia y Etnografía," 244; Tschohl y Nikel, Catálogo arqueológico y etnohistórico de Puebla-Tlaxcala, 340.

51 Alzate, "Sobre el origen de los mexicanos," 82.
} 
Marquina -quien en ese entonces era el Director de Prehispánicos del INAH - , ayudó a formar el arqueólogo Palacios entre otros investigadores de esa dirección, indicó con respecto a las ruinas de Libres dentro del municipio y cercanas a la estación de ferrocarril del mismo nombre, citó como una de las fuentes bibliográficas de donde obtuvo su información, "J.R.F. Cañete. Gaceta de Literatura, 1790". 52 Esta última, como ya hemos señalado, no es otra que la misma noticia del señor Cañete que estamos tratando; sin embargo, aquí en este atlas se utilizó como referencia del sitio de Libres y no de Cantona o Cantonal en cuya respectiva bibliografía no aparece y se ofrece como su referencia más temprana el artículo en francés titulado "Descubrimiento de las Ruinas de una Antigua Ciudad Mexicana, situada sobre la Altiplanicie de Anáhuac" publicado ${ }^{53}$ en el año de 1858 por el ginebrino Henri de Saussure, el que según Palacios, es el descubridor de estas últimas ruinas ${ }^{54}$ que denominó "la ciudad del Cantón". 55

No obstante lo anterior, esta última denominación también aparece en una lámina a lápiz que fue dibujada por el capitán Guillermo Dupaix producto de sus "correrías particulares" a estas ruinas y por otros varios sitios arqueológicos de la Nueva España cuando todavía ocupaba el cargo de capitán del Regimiento de Dragones de México ${ }^{56}$ y antes que encabezara la Real Expedición Anticuaria de la Nueva España entre los años de 1805-1809 la que recibió el apoyo de Carlos IV. ${ }^{57}$ Esta lámina muestra una pirámide truncada con taludes corridos y una escalera sin alfardas en su fachada para ascender a su cima. El dibujo es una representación de uno de los basamentos piramidales -quizá de alguno de los que fueron consolidados en los primeros años de última década del siglo xx por el proyecto Especial

52 Véase en dicho Atlas arqueológico de la República Mexicana, 190.

53 Véase en el mismo Atlas arqueológico de la República Mexicana, 187.

54 Palacios, "Hueyaltépetl," 189.

55 Saussure, "Découverte des Ruines D'une Ancienne Ville Mexicaine, située sur Le Plateau de L'Anahuac [Descubrimiento de las Ruinas de una Antigua Ciudad Mexicana, situada sobre la Altiplanicie de Anáhuac]," 293.

56 López Luján, "El capitán Dupaix y su álbum arqueológico de 1794," 2011, 72; López Luján, El Capitan Guillermo Dupaix y su álbum arqueológico de 1794, 2015, 43 y 68-69; López Luján y Arlette, "Las 'correrías particulares' del capitán Guillermo Dupaix," 79; Estrada de Gerlero, Guillermo Dupaix, precursor de la historia del arte prehispánico, 45.

57 Dupaix, Expediciones acerca de los antiguos monumentos de la Nueva España, 1805-1808; Dupaix, Atlas de las Antigüedades mexicanas halladas en el curso de los tres viajes de la real expedición de antigüedades de la Nueva España, emprendidas en 1805, 1806 y 1807; Palop y Cerdá, "Nuevos documentos sobre las expediciones arqueológicas de Guillermo Dupaix por México. 1805-1808," 129-152; Estrada de Gerlero, "La Real Expedición Anticuaria de Dupaix," 168-181. 
Cantona del INAH - que se localizan en la hoy denominada Acrópolis de la zona arqueológica de Cantona. En la parte superior de dicha lámina, Dupaix escribió con letra a tinta: "33/Antigua ciudad (o ruinas) en el malpaís cerca de la hacienda de Tezontle, cerca de Tepeyahualco, camino de Perote. Pirámide truncada al uso de los antiguos llamada modernamente Canton, revestida de piedras esquadradas". 58 Dicha lámina es un excelente documento que da cuenta que Dupaix visitó las anteriores ruinas hoy denominadas de Cantona en el malpaís de la hacienda de Tezontepec -la que él denominó de Tezontle- cercanas a Tepeyahualco, varios años antes de que dirigiera la ya mencionada Real Expedición Anticuaria de la Nueva España. Sospechamos que la decisión del capitán luxemburgués de ir a inspeccionar las ruinas de Cantón, la realizó gracias a la lectura que hizo sobre el artículo del Origen de los mexicanos del que quizá se pudo enterar cuando leyó la ya referida noticia de Alzate sobre las ruinas de la Xochicalco.

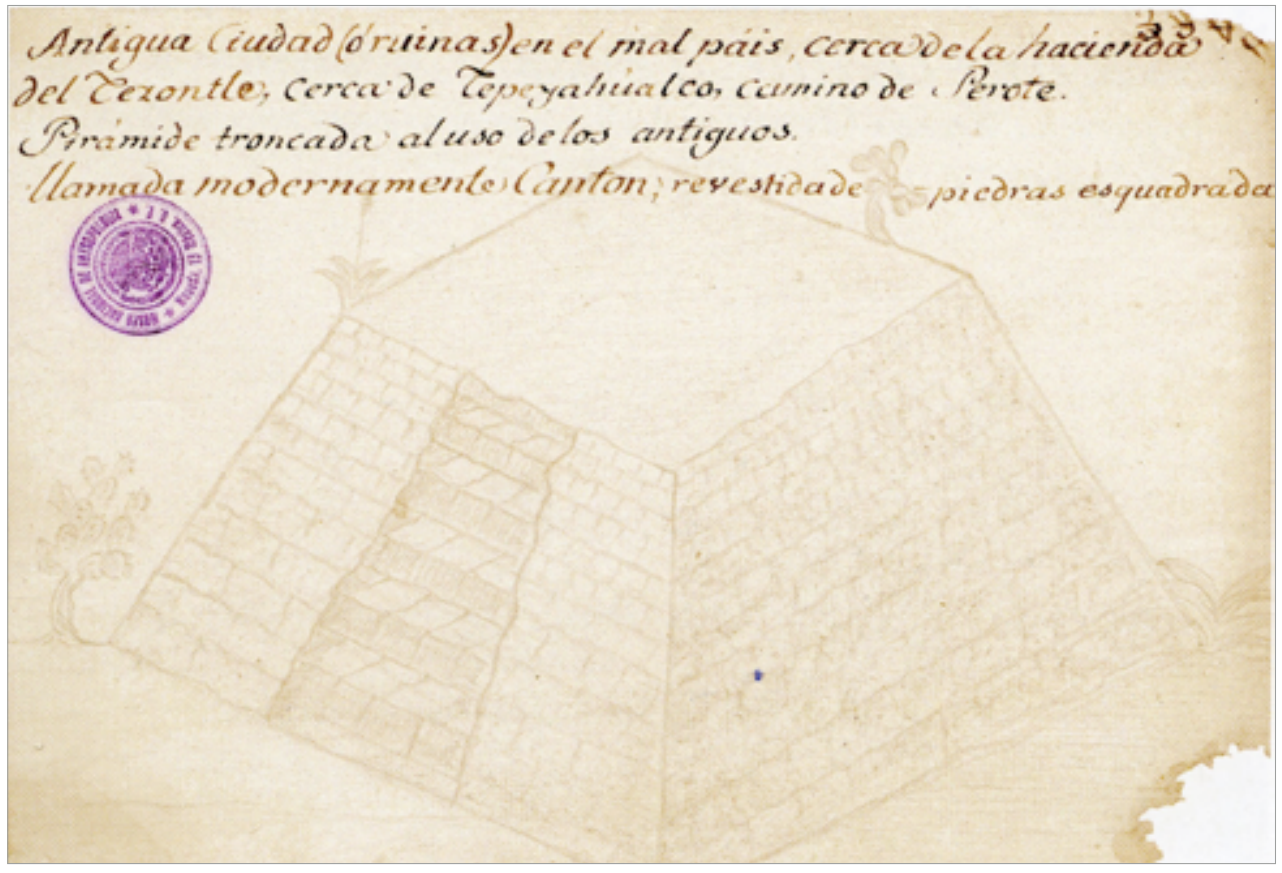

Regresando a la descripción sobre el antiquísimo poblado en la jurisdicción de San Juan de los Llanos (véase anexo), que el jurisprudente e instruido en Matemáticas e Historia Civil, Joseph Francisco Ruiz Cañete redactó en la capital virreinal y
Lámina de la antigua ciudad

llamada modernamente

Cantón (INAH-CDBNAH,

Dibujos Guillermo Dupaix,

caja 3, lámina número

inventario 75, $21.2 \times 30.08 \mathrm{~cm}$;

Estrada, 2017: 19.4, 196).

Digitalización:

J.H. Medina González.

58 Dibujos Guillermo Dupaix, caja 3, lámina número inventario 75, $21.2 \times 30.08$ cm, INAHCDBNAH; López Luján y Arlette, "Las 'correrías particulares' del capitán Guillermo Dupaix," foto de lámina, 87; López Luján, El Capitán Guillermo Dupaix y su albúm arqueológico de 1794, 2015, 69 y fotos de la lámina y de la pirámide en la Plaza Central de Cantona, 62; Estrada de Gerlero, Guillermo Dupaix, precursor de la historia del arte prehispánico, 2017: 19.4, 85 y foto de lámina, 196. 
remitió con fecha del 17 octubre de 1786 al bachiller; quien a su vez la publicó - sin modificación alguna, aunque le agregó 12 notas al pie- en su Gazeta de Literatura tres años después, no sin antes confrontarla con otra noticia descriptiva muy semejante aunque más pobre en información sobre dichas ruinas, que también recibió de otra persona que residió en esa misma jurisdicción, podemos señalar lo siguiente: El jurisprudente escribió que a una distancia de 140 leguas ${ }^{59}$ de la Ciudad de México y con dirección al noreste se encontraba ese ancestral poblado cuyo nombre original se desconoce y que fue abandonado siglos antes de la conquista de la Nueva España por la falta de agua. Según él, esta antigua ciudad, ya en ruinas, se componía por aproximadamente 30 mil casas, unas más grandes que otras, solares, patios, cues, adoratorios, calles y callejones, los que se extendían sobre una superficie de una legua $(5.572 \mathrm{~km})$ de este a oeste y $3 / 4$ de legua $(4.1179 \mathrm{~km})$ de norte a sur, dentro de las tierras de agostadero de un rancho de sus antepasados al que no había regresado en tres décadas. De ahí que su descripción fuera redactada gracias a lo que escuchó de sus rebisabuelos y de su padre mismo, así como de los recuerdos que aún guardaba cuando por su afición por la caza se internaba en esas tierras, las que desde antes que se fundara el rancho ya estaban todas cubiertas por una densa maleza y árboles de pino, encino y sabino. Varios de estos árboles, que mostraban una apariencia muy vetusta, habían crecido en las casas y solares mientras que un ocote de mucha altura estaba en la parte superior de una torre o $\mathrm{Cu}$. De las vías de comunicación indicó que las calles no mostraban ningún orden, aunque entre unas posesiones y otras mediaban unos callejones muy estrechos. Y había una enorme calzada que atravesaba este inmenso asentamiento de este a oeste, cuyo arroyo de circulación además de estar delimitado por muros laterales muy altos, también estaba pavimentado con lajas muy desgastadas debido al intenso tráfico humano y peldaños para subir o bajar, dependiendo los cambios de nivel durante su recorrido. Igualmente registró los vestigios de gruesas paredes de mampostería con una altura de entre 2 y 4 varas ${ }^{60}$ cuyas rocas - sin trabajar- con las que fueron erigidos no muestran ningún cementante y sí una enorme habilidad para haber sido apretujadas, acuñadas y "entrelazadas" unas con otras, y añadió que también había mucha roca "labrada" en los ya referidos "Cues y Adoratorios", coincidiendo plenamente con lo documentado años después por Dupaix en cuya lámina antes referida sobre la antigua pirámide truncada de las ruinas del Cantón, escribió que "estaba revestida con piedra labrada". Sin embargo, mucha de esta última había sido retirada para formar las esquinas de las construcciones, los pisos de los patios y los graneros.

59222 km, según Cortés I. y Ramírez G, Rescate de antiguas medidas iberoamericanas, una legua mexicana equivale aproximadamente en distancia a los 5,572.70 m.

601.67 a 2.51 m, según Cortés I. y Ramírez G, Rescate de antiguas medidas iberoamericanas, una vara mexicana equivale $83.80 \mathrm{~cm}$. 
De igual manera, el Lic. Cañete no sólo escribió sobre las excavaciones que él mismo ejecutó dentro de un enorme solar de las que extrajo la mesa monolítica antes descrita y en cuyas cercanías encontró una estatua antropomorfa que fue tallada sobre piedra cantera y cuyos detalles describió de manera muy somera, sino también de aquellas excavaciones que realizó su padre, quien le contó sobre el hallazgo de una escultura de un felino tallado sobre roca, la que llevó hasta una iglesia y en cuya cabeza colocó una pila con agua bendita. Entre otros hallazgos reportados en estas ruinas, se mencionan otras esculturas en roca, cajetes, restos de cerámica e instrumentos en lítica para la molienda, los que según la apreciación del licenciado eran todos toscos y en grandes cantidades. También en su narrativa hizo mención de la flora nativa que crecía sobre las ruinas, algunas de ellas comestibles, como por ejemplo de los magueyes de los que obtiene un muy buen pulque cuya calidad supera al común. Finalmente, regresando a los párrafos escritos por Alzate que introducen al lector a esta descripción, en ellos el erudito mexicano anima a otras personas curiosas e instruidas que puedan documentar con mayores detalles esta antigua urbe abandonada para que acaso se puedan demostrar otros conocimientos que se pueden considerar útiles como los que él obtuvo producto de las inspecciones arqueológicas que hizo a las ruinas de Xochicalco unos años antes.

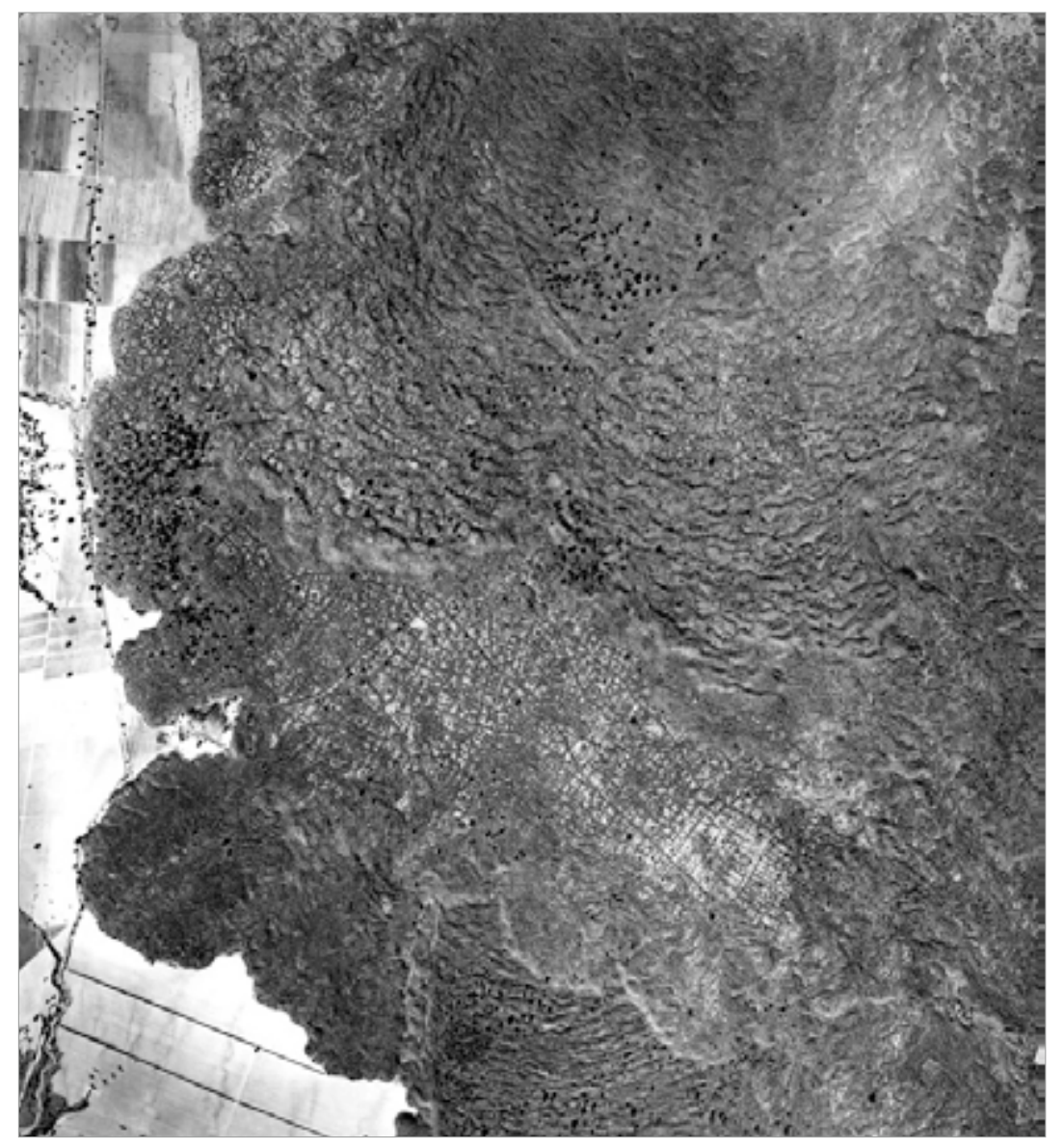

Foto aérea con las coladas de lava del malpaís donde se extienden una parte de los vestigios de la retícula de unidades habitacionales, calles, calzadas y la Acrópolis en la sección sur de la ciudad prehispánica de San Juan de los Llanos, Cantón o Cantona, Puebla (J.P.F.F. Puebla Forestal, Obra 2754, [escala] 1:20.000.-23-11-82 D.F.152.13MM C.M.A -R2577, F89, 00041, n.316, 4396, 152,13). Digitalización: J.H. Medina González. 

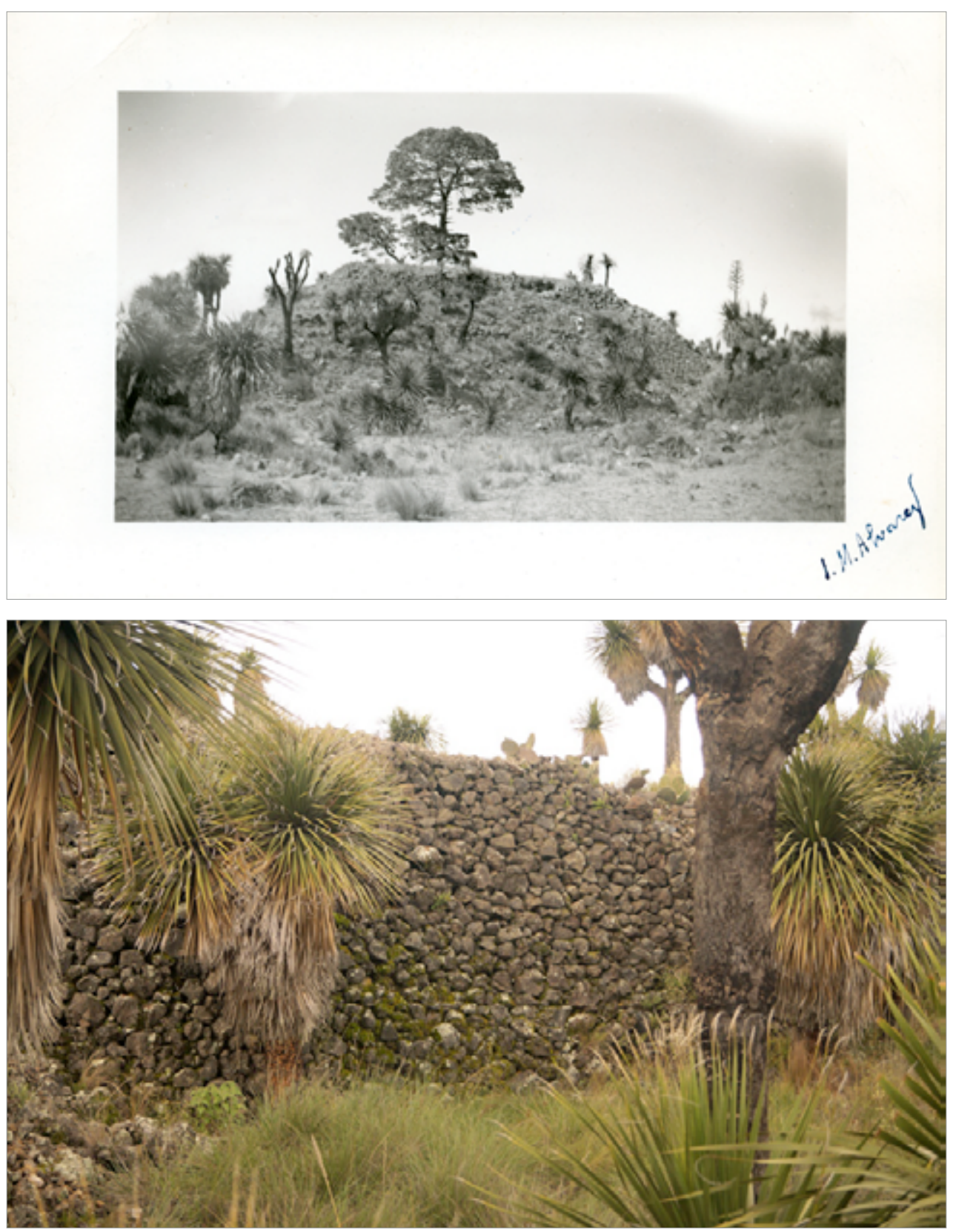

"Adoratorio" o montículo en las ruinas de Cantona, Puebla, 1935. Foto: Ismael M. Álvarez (INAH, ATCNA, Depto.de Monumentos Prehispánicos, Zona Arqueológica Cantona, B/311.42 [Z47-8] [044] 1). Digitalización: J.H. Medina González y Guadalupe Martínez.
Muro muy alto aún en pie en el sector Sur de Cantona. Foto: arqueólogo Cuauhtémoc Domínguez Pérez, 2018, Proyecto Especial Cantona/INAH.

\section{Reflexiones finales}

De lo antes expuesto, coincido con lo señalado por el historiador Echenique, ${ }^{61}$ que uno de los principales intereses de Alzate para publicar su artículo "Sobre el origen de los mexicanos" -que apareció en el número 11 del 8 de febrero de 1790 de su

61 Echenique March, "Ensayo. José Alzate y Ramírez, impulsor intelectual de José Mariano Moziño y sus noticias del puerto de San Lorenzo de Nutka en la Nueva California." 
Gaceta de Literatura - era que al circular ese ejemplar por la antigua capital de México, su información se conociera rápidamente entre sus lectores, las autoridades del virreinato de la Nueva España y de la Corona española, y así se tuviera un alegato contra el Reino Unido de Gran Bretaña -y quizá también con otras superpotencias europeas que rivalizaban por el control de las rutas de navegación, comercio, posesión, ocupación de grandes regiones geográficas en el Nuevo Mundo- para poder reclamar como derecho legítimo de España su dominio territorial de la isla del Nutka, no sólo por su descubrimiento en 1774 por el piloto Juan Pérez o por su posesión en los años siguientes por otras expediciones navales españolas, sino muchos siglos antes de la llegada de las primeras embarcaciones británicas a la costa noroeste del Pacifico en la América del Norte como aquella del capitán Cook en 1788 o de los demás ingleses y rusos que lo antecedieron. Utilizando un método de estudio que hoy podríamos denominar etnográfico-histórico-arqueológico, Alzate escribió en los primeros párrafos de su artículo, una muy breve narrativa en la que expuso cómo ciertos rasgos culturales, que según él, compartían los nutkenses de la Costa Noroeste de Norteamérica y los indígenas otomís y mexicanos del centro de México, a quienes los separaban miles de kilómetros, podían explicarse por qué muchos siglos antes de que esos pueblos llegaran a sus respectivos territorios donde finalmente se asentaron (y hoy se encuentran), partieron de un mismo lugar de origen conocido como la Laguna de Tehuallo o Teguayo. En la tradición de los grupos indígenas del septentrión novohispano, en la autoridad de lo escrito por ciertos historiadores y en las fuentes históricas a las que Alzate tuvo acceso que se encontraban en el Archivo de la Secretaría del Virreinato y en otros acervos documentales de la capital novohispana, se encontraban lejanas memorias y otras informaciones sobre esa ancestral laguna. De ella se decía que de sus alrededores en una época muy remota, partieron muchas de las naciones indígenas que poblaron esta tierra y después se dispersaron en sus inmensos territorios, ${ }^{62}$ incluidos los antiguos mexicanos quienes fueron los últimos en salir de allá. Testimonios materiales de la salida de esos "primeros" mexicanos son los antiguos vestigios de sus mansiones que dejaron en las inmediaciones del lejano Teguallo y más cercanamente al sur en Arizona, EE.UU. y Chihuahua, México, que son las estaciones dejadas por ellos en el septentrión durante su largo camino hacia el centro de la Nueva España. Gracias al manejo de mucha de esta información, Alzate ubicó cartográficamente la fabulosa Laguna de Tehuallo o Teguayo en los límites más septentrionales de la Nueva España, como se puede corroborar en sus mapas antes referidos, ya que más allá de ese horizonte conocido se encontraba la lejana isla del Nutka cuyas coordenadas geográficas también dejó registradas en su artículo. Pero lo que resulta muy interesante en los primeros párrafos de este último, es que para construir con la más sólida argumentación su alegato que

62 Tyler, "The myth of the Lake of Copala and Land of Teguayo," 323. 
justificara por qué el Nutka y sus habitantes indígenas pertenecían al dominio de ultramar de la Corona de España, Alzate tuvo en sus manos las publicaciones y fuentes documentales -todas las ya citadas antes - con la mejor información etnológica, histórica y de las antigüedades que en ese momento había en la capital de la Nueva España. Publicaciones como la del Capitán Cook - la que se sospecha que traían bajo el brazo los capitanes ingleses James Colnett y Thomas Hudson cuando estuvieron presos en la ciudad de México-, la del Arzobispo Lorenzana; manuscritos de primera mano redactados en los siglos XVII y XVIII por historiadores, funcionarios del virreinato, militares, misioneros jesuitas y otros eclesiásticos que incursionaron en los extensos territorios de las Provincias Internas y más al norte, le proporcionaron las pruebas más directas y quizá con mayor "veracidad" que dieron apoyo a su argumento que brevemente expuso al principio de esa gaceta. Con respecto al reporte escrito en octubre de 1786 por el Licenciado en jurisprudencia Ruiz Cañete sobre la antigua población de San Juan de los Llanos (hoy Zona Arqueológica de Cantona), el que cuatro años después Alzate publicó en esta última, por la única razón que en ella se estaban tratando el asunto de las antigüedades, se puede señalar, que fue la primera noticia de unas ruinas arqueológicas mexicanas que editó el erudito novohispano; su descripción del antiguo castillo-fortaleza de Xochicalco, como ya se indicó, salió en 1791 en un suplemento de la Gazeta de Literatura. Resulta interesante que en esas gacetas en las que se describen dos monumentos arqueológicos del periodo Epiclásico mesoamericano -como Cantona y Xochicalco que fueron encontrados en suelo mexicano- salieran a la luz pública en fechas que en la Nueva España ocurrieran importantes sucesos: el primero vinculado con una empresa marítima militar a la costa noroeste de Norteamérica que ordenó realizar en 1790 el Segundo Conde de Revillagigedo entonces virrey de la Nueva España, y un año después con asuntos relacionados con la más grande expedición científica de ultramar que fue financiada por la Corona española durante la época ilustrada de Carlos III. La empresa naval no es otra que la ya mencionada salida de los navíos españoles bajo el mando del teniente Francisco Eliza desde el puerto San Blas en la costa de Nayarit, para volver a ocupar la isla del Nootka y el juicio que se hizo ante la Audiencia de México de los dos capitanes ingleses a comienzos de 1790, ambos acontecimientos, en los días siguientes, animaron al editor de la gaceta para imprimir su artículo "Sobre el origen de los mexicanos". Y en los primeros meses de 1791, la presencia en la Nueva España de los comisionados de la Expedición Marítima Alrededor del Mundo o Expedición Malaspina a cuyo cargo se encontraba el comandante toscano Alejandro Malaspina. Fue tal la admiración del editor de la gaceta por esta expedición (la que también pasó por el Nutka), que les dedicó su descripción de las antigüedades de Xochicalco en el suplemento que salió a finales de ese año. ${ }^{63}$ Se debe señalar

63 Tyler, "The myth of the Lake of Copala and Land of Teguayo," 323. 
que durante las breves estancias que algunos de esos comisionados hicieron en la capital, Alzate intercambió con ellos saberes, información y descubrimientos científicos de las investigaciones que estaban en marcha, los acompañó en excursiones a los alrededores de la ciudad de México, les abrió su biblioteca, los asesoró sobre varios asuntos y con Malaspina, que tenía un enorme interés por la arqueología, ${ }^{64}$ sostuvo un amplio diálogo sobre varios asuntos de la misma. Resulta muy sugerente pensar, que todo este creciente clima de interés científico que trajo consigo la Excursión Marítima de Malaspina a la Nueva España, haya sido el principal motor que animó al ilustrado mexicano, para que finalmente sacará a luz pública su reporte sobre Xochicalco producto de sus inspecciones realizadas a esas ruinas en los años de 1777 y $1785 .{ }^{65}$ Años después de su publicación, el famoso Guillermo Dupaix consultó ese suplemento que lo condujo irremediablemente al impreso "Sobre el origen de los mexicanos". De la lectura de su apartado sobre el antiguo poblado de San Juan de los Llanos, el entonces Capitán de Dragones, tomó la decisión de llevar a cabo una "correría particular" a sus ancestrales vestigios, los que registró con el nombre de ciudad o ruinas del Cantón (hoy denominadas de Cantona). Lo anterior apoya mi sugerencia de que el arqueólogo-viajero luxemburgués consultó esas dos gacetas quizá antes de inspeccionar directamente los vestigios de esa antigua ciudad y los de Xochicalco, como también lo hizo con las ruinas del Tajín, Veracruz, una vez que leyó el número 42 de la Gaceta de México que salió el martes 12 de julio de 1785, en la que su impresor Manuel Valdés, imprimió la primera noticia que hasta hoy se tiene sobre los restos arquitectónicos de la hoy denominada Pirámide de los Nichos que también se erigió durante el periodo Epiclásico. Es importante señalar que aún nos falta por conocer con mayor profundidad cómo le surgió a Alzate el interés por el conocimiento de las antigüedades mexicanas, qué lo animó a comenzar su estudio y publicar en su gaceta los dibujos y escritos sobre ellas que elaboraron él u otras personas y qué ideas tenía sobre la información del pasado que se podía extraer de su estudio y la utilidad que se podía obtener de su conocimiento. Sólo conozco que en su referida descripción sobre Xochicalco del suplemento, Alzate escribió un párrafo ${ }^{66}$ en el que claramente señaló, que los antiguos monumentos arquitectónicos de los indios mexicanos que aún quedaban, a pesar de

64 González Claverán, La expedición científica de Malaspina en Nueva España 1789-1794, 101.

65 Alzate, "Descripción de Antigüedades de Xochicalco. Dedicada a los Señores de la Actual Expedición Marítima Alrededor del Orbe," 1.

66 Se transcribe párrafo: "I.-Los monumentos de Arquitectura de las Naciones antiguas, que permanecen á pesar de las injurias del tiempo, sirven de grande recurso para conocer el caracter de los que fabricaron, siempre que hay falta de Autores coetaneos, como también para suplir á la omisión ó mala fe de los Historiadores. Un Edificio manifiesta el caracter y cultura de las gentes; por que es cierto que la civilidad ó barbarie se manifiesta por el progreso que las Naciones hacen en las Ciencias y Artes." (Alzate 1791, 2) 
lo sucedido por el transcurso del tiempo, pueden ser considerados un importante recurso de información para averiguar el grado de progreso -civilización o barbariede esas ancestrales naciones indígenas que los erigieron, ante la falta de testimonios de autores contemporáneos o bien para sustituir el olvido y malicia de los historiadores. Él estaba convencido de que de la descripción minuciosa de esos vestigios que aún quedaban de las bellas y ancestrales edificaciones mexicanas, se podían sacar sólidas pruebas sobre el alto conocimiento alcanzado por los indígenas en las ciencias y en el arte, las que contradicen las falsas impresiones que se tienen de ellos o pésimos juicios contra los mismos que se leen en los escritos editados por escritores principalmente extranjeros como Pauw y Robertson. De ahí que consideró que esos vestigios materiales de la antigüedad eran evidencias mucho más convincentes y persuasivas que, al ser directamente examinadas, podían servir para validar y a la vez cuestionar - por la tergiversación de los hechos- la autoridad de lo escrito en los textos, especialmente de aquellos referentes a los indios de México que habían sido publicados por los anteriores estudiosos extranjeros. Al sentirse Alzate convencido de todo lo anterior y al abrirse la oportunidad de viajar al sur de la capital del virreinato con destino hacia Cuernavaca en diciembre de 1777, antes de partir indagó sobre las curiosidades de interés que podían hallarse en su trayecto por esa región. Se le advirtió que visitara el castillo de Xochicalco que en lengua mexicana quiere decir "casa de las flores". Sabía que si realizaba esa inspección, por primera vez podría examinar directamente en campo una arquitectura tan preciosa, como los vestigios de un antiguo palacio del que le habían hablado y de sus otros arruinados monumentos, de cuya descripción extraería sólidas demostraciones que añadiría a su argumentación en contra de los prejuicios y la enorme ignorancia con la que se había escrito sobre los indios mexicanos. Hoy sabemos, gracias a las publicaciones de las investigadoras Cabello Carro ${ }^{67}$ y Estrada de Gerlero, ${ }^{68}$ que el mismo año cuando Alzate ejecutó esa primera inspección a Xochicalco, el naturalista, militar y escritor español Antonio de Ulloa, jefe de escuadra y comandante general de la flota que se hallaba en Veracruz, redactó el "Cuestionario para la formación del completo conocimiento de la geografía física, antigüedades, mineralogía y metalurgia de este reino de la Nueva España e instrucción para formarlo." 69 Ulloa recibió todas las facilidades por parte de José de Gálvez, en ese entonces Secretario de Indias, para que mediante dicho cuestionario e interrogatorio se reuniera un acervo de noticias geográficas y científicas que contribuyera a mejorar el conocimiento de la

67 Cabello Carro, "La Arqueología Ilustrada en el Nuevo Mundo," 267.

68 Estrada de Gerlero, "La Real Expedición Anticuaria de Dupaix," 168.

69 Solano, Antonio de Ulloa y la Nueva España, CXLIV-CLI; Solano (editor), Cuestionarios para la Formación de las Relaciones Geográficas de Indias Siglos XVI / XIX, 177-183. 
Nueva España. Una vez que terminó de redactar el cuestionario el 22 de enero de 1777, se lo mandó al virrey de la Nueva España, Antonio María de Bucareli y Ursúa, quien a su vez ordenó que se imprimieran varios ejemplares del mismo para ser enviados y repartidos en las provincias del virreinato para que militares, funcionarios del gobierno y personas eclesiásticas levantaran descripciones de las ciudades villas, pueblos y de sus jurisdicciones. ${ }^{70}$ El resultado de aquellos interrogatorios que fueron levantados en las diferentes regiones de la Nueva España son las Relaciones de los pueblos de México del siglo XVIII, también conocidas como Descripciones o relaciones geográficas del Virreinato de la Nueva España, que datan de los años de $1777 \mathrm{y}$ $1778^{71}$ y que, a semejanza de aquellas Relaciones geográficas del siglo XVI, proporcionan valiosa información geográfica, hidrológica, climatológica, botánica, zoológica, agrícola, ganadera, metalúrgica, mineralógica, así como sobre otros aspectos relacionados con la historia natural, como son de las petrificaciones (restos fósiles) y los testáceos, entre otros temas. De igual manera, debido a los intereses de Ulloa por el remoto pasado indígena, ${ }^{72}$ en su cuestionario o interrogatorio y en las relaciones geográficas resultantes aparecen preguntas e información sobre las antigüedades (monumentos arqueológicos, vasijas, herramientas, armas, ídolos, sepulcros, insignias, adornos, restos de ropajes, etc.), así como detalles etnográficos sobre las costumbres y vestimenta de los pueblos indígenas del siglo XVIII. ${ }^{73}$ Como ya indicamos, el inmediato interés de Alzate por el cuestionario e instrucción de Ulloa que se imprimió a principios de 1777, quizá lo animó a visitar las ruinas de Xochicalco en diciembre de ese mismo año y lo entusiasmó a escribir un primer documento -que antecedió 14 años al finalmente publicado-, con el que "El difunto doctor Gamarra, formó un compendio que remitió a Italia que acaso se habrá impreso."74 Otra preciosa memoria con incomprensibles láminas producto de esa visita arqueológica, se la entregó al virrey Bucareli con una dedicatoria en la que escribió varias lindezas

70 Solano (editor), Cuestionarios para la Formación de las Relaciones Geográficas de Indias Siglos XVI / XIX, 31.

71 Solano, Antonio de Ulloa y la Nueva España, XLIX-L.

72 Solano, "Don Antonio de Ulloa, Paradigma del Marino Científico de la Ilustración Española," 341-342.

73 Carrera, "Relaciones Geográficas de la Nueva España Siglos XVI y XVIII, " 252.

74 Alzate, "Descripción de Antigüedades de Xochicalco. Dedicada a los Señores de la Actual Expedición Marítima Alrededor del Orbe," 1791, 1; Alzate, "Descripción de Antigüedades de Xochicalco. Dedicada a los Señores de la Actual Expedición Marítima Alrededor del Orbe," 1831 [1791], 1 y Alzate, "Descripción de antigüedades de Xochicalco. Dedicada a los señores de la actual expedición marítima alrededor del orbe," 2012 [1791], 417; Moreno de los Arcos, "Efemérides de José Antonio Alzate y Ramírez," 40. 
sobre su gobierno, que evidentemente no salió a la luz pública. ${ }^{75}$ De ahí que la memoria o descripción sobre Xochicalco a la que Alzate le agregó sus segundas observaciones realizadas en esas ruinas gracias a la otra expedición que realizó en 1784, se editara hasta 1791 en su ya referido suplemento de la Gazeta de Literatura, mismo año que según Cabello Carro, ${ }^{76}$ el erudito novohispano también editó en este diario las instrucciones de Ulloa. Fueron las últimas que fueron impresas en 1777 por el virrey Bucareli y que circularon entre muchas de las intendencias de la Nueva España y estuvieron a la vista en muchos lugares, lo que seguramente facilitó para que Alzate inmediatamente las consultara. De su lectura, él adquirió ese temprano interés por el conocimiento de las antigüedades, ¿qué información del pasado encierran? y de cuáles se debe de dar noticias. Señalándose a las ruinas de las ancestrales edificaciones de la Gentilidad, como pueden los vestigios de varios de sus elementos constructivos, los sepulcros dentro de construcciones religiosas y habitación, diversos tipos de artefactos para la subsistencia, (objetos ceremoniales, insignias, armamento entre otros) y por último, el registro de las vestimentas de los indígenas vivos y de los materiales con los que estaban manufacturados. ${ }^{77}$ Pero sí de la consulta de estas instrucciones y del cuestionario, el erudito novohispano obtuvo ese temprano interés por el estudio de los restos materiales del pasado antiguo; qué fuente documental consultó sobre ese método comparativo -o muy probablemente él lo construyó-, que aquí denominamos etnográfico-histórico-arqueológico entre comunidades indígenas americanas separadas por enormes territorios de cuyos rasgos culturales y testimonios materiales de la antigüedad se podía encontrar su ancestral lugar de procedencia, como lo expuso en su artículo "Sobre el origen de los mexicanos". Propongo como hipótesis a investigar, que Alzate muy probablemente tuvo en sus manos otro libro publicado en España en 1772 (hay otra edición 1789) del mismo Antonio de Ulloa, titulado Noticias Americanas: Entretenimientos PhisicosHistóricos, Sobre La América Meridional y Septentrional Oriental. Comparación General De los Territorios, Climas, Producciones en las tres especies, Vegetales, Animales y Minerales: Con Relación Partícular De las Petrificaciones de Cuerpos Marinos de los Indios naturales de aquellos Paises, sus usos y costumbres, y usos: De las Antiguedades: Discurso sobre La Lengua y sobre el Modo en que pasaron los primeros pobladores. En la introducción de esta publicación, producto de sus viajes de expedición y residencia en la América Meridional y de la que cinco años después derivó sus ideas para el apartado de las antigüedades para sus Instrucciones y Cuestionario de 1777 para la Nueva España, Ulloa escribió:

\footnotetext{
75 Moreno de los Arcos, "Un eclesiástico frente al estado Borbón," 21.

76 Cabello Carro, "La Arqueología Ilustrada en el Nuevo Mundo," 267.

77 Solano, Francisco de, Antonio de Ulloa y la Nueva España, CXLVIII.
} 
Las memorias de antiguedad son las demostraciones veridicas de lo que fueron las gentes en los tiempos á que se refieren: por ellas viene á averiguarse lo que alcanzaron, el modo en que se manejaron, su gobierno, y economía; y á este respecto lo que han adelantado, ó perdido, lo numeroso de sus gentíos, la industria, el valor, y las máximas de manejarse, sin los monumentos, que, sin embargo de la ruína de los tiempos, se conservan en alguna parte, no habría documentos formales por donde inferirlo. De ellos se comprehende la semejanza que tubieron unos Pueblos con otros, y por este medio llega, en aquella forma que es posible, á desentrañarse su origen, que es una de las particularidades que mas incitan el deseo, como sucede con los Indios, que por estár separados de las otras tierras, y por tener disonancia en el color, y en otros accidentes de la contestura, dificulta el juicio el modo de haber transitado á poblar, y el origen de donde salieron. Estos asuntos serían de la mayor confusion para el entendimiento si no se les encontrase una solución regular en los vestigios de la cosas, las costumbres, y las demás particularidades que descubre la investigación, ayudada de la inteligencia. ${ }^{78}$

Considero de enorme relevancia corroborar si Alzate efectivamente tuvo en sus manos este libro, por las enormes analogías que hay entre éste y las ideas que aparecen en su artículo "Sobre el origen de los mexicanos" y el párrafo de Ulloa antes citado. Para ambos era posible desentrañar el lugar de procedencia de los indios a partir del estudio y rastreo de los vestigios materiales del pasado (antigüedades y ruinas de monumentos) y de la comparación de las costumbres de pueblos separados miles de kilómetros por las enormes distancias que transitaron para llegar hasta el lugar donde finalmente se asentaron. Quizá a futuro, para comprender con mayor claridad las investigaciones realizadas en las últimas décadas del siglo XVIII sobre los vestigios arqueológicos de las sociedades indígenas precolombinas encontrados y exhumados en el actual territorio mexicano, los investigadores tendremos que conocer mejor los intereses geopolíticos y científicos de las empresas navales y expediciones científicas a ultramar que por esas décadas fueron respectivamente financiadas y enviadas por el virreinato de la Nueva España y la Corona de España. -

78 Ulloa, Antonio. Noticias Americanas: Entretenimientos Phisicos- Históricos, Sobre La América Meridional y Septentrional Oriental. Comparación General De los Territorios, Climas, Producciones en las tres especies, Vegetales, Animales y Minerales: Con Relación Partícular De las Petrificaciones de Cuerpos Marinos de los Indios naturales de aquellos Paises, sus usos $y$ costumbres, $y$ usos: De las Antiguedades: Discurso sobre La Lengua y sobre el Modo en que pasaron los primeros pobladores, sin paginación. 


\section{Anexo}

$\begin{array}{lll}\text { T. I } & \text { Núm. } 11 \quad \text { Pág. } 81\end{array}$

[Sobre el origen de los mexicanos]

GAZETA DE LITERATURA

MEXICO 8 DE FEBRERO DE 1790

[José Antonio Alzate y Ramírez]*

Asi como el de las mas Naciones, se confunde en las tinieblas de la Antiguedad. Algunos Historiadores aseguran partieron del Norte, de las inmediaciones de la Laguna de Tehuallo ${ }^{(a)}$ para venir á establecerse en lo que se conoce por Nueva España. La tradicion que conservan las Naciones del Norte sirven de apoyo á esta idea, como tambien las antiguedades que aún permanecen, y son las que se conocen por Casa Grande $^{(b)}$ á las orillas del Rio Guila, y la de Casas grandes ${ }^{(c)}$ en las inmediaciones del Presidio de Janos.

No sé si lo que voy á referir contribuirá á patrocinar esta emigracion de los Mexicanos del Noreste al Sueste; lo cierto es que registrando los viages del célebre Capitan Cooc, veo pinta á los Indios del Puerto de San Lorenzo de Nootca vestidos con trage muy semejante al de muchos Pueblos de Nueva España, principalmente los Otomites habitantes del Valle de Toluca, y á su Poniente. Las mujeres se vén retratadas con el pelo suelto, lo mismo que acostumbran las Indias Otomitas del mencionado Pais., pero lo mas particular es, que dibujando $\operatorname{Cooc}^{(\mathrm{d})}$ lo interior de una de las casas

* Transcripción completa del impreso de la Biblioteca Nacional de México, se respetó su ortografía original. El título y el nombre del autor de la publicación escritos dentro de los corchetes es agregado de J.H.M.G.

(a) La Laguna de Tehuallo se halla en 41 grados de latitud y en 265 y medio de longitud.

(b) Casa grande en 34 y medio de latitud, y 259 y medio de longitud.

(c) Casas grandes en 31 y medio de latitud al sur del Presidio de Janos: los habitantes del Noroeste de Nueva España, aseguran que estos tres sitios, quiero decir en los que se registran restos de Poblaciones, el primero al Sur de Tehuallo en 38 grados de latitud, 254 de longitud, y los otros dos, son en los que hicieron mansion los Mexicanos, y los conocen por dichas denominaciones.

(d) Estampa número 41 de los trages de los Nootca. Estampa 42 los Pilastrones con relieve. Viaje tercero de Cooc. 
del Puerto de Nootca, se registran dos pilastrones con figuras de medio relieve en todo semejantes al estilo(e) que tenian los Mexicanos, para esculpir sus Geroglificos. Registrense los pocos monumentos que aún restan de los antiguos Mexicanos, y las láminas insertas en la reimpresión de las Car-

82.

tas de Cortés, executada en México en 1770: comparece con los que pinta Cooc, y se palpará la identidad que hay de escultura á escultura.

Si á esta reflexa se añade la de estar Nootca 49 1/2 grados de latitud, y suponerse por algunos Historiadores que la Laguna de Tehuallo se halla en 41 grados, parece que todo esto puede patrocinar, y en algun modo aclarar punto tan interesante en la Historia. Si el Capitan Cooc hubiese presentado un pequeño índice de las voces de la lengua de los Nootcacos sin alterar la pronunciación, se podrian comparar con las del idioma Mexicano, para reconocer si tienen alguna analogia, bien que la pronunciación de aquellas gentes debe ser áspera, no dulce, como la de los Mexicanos, lo que proviene en mucha parte de la diversidad de los climas. ${ }^{(\mathrm{f})}$

Ya que trato de antiguedades trasladaré la noticia que de una antigua poblacion me comunicó el Licenciado D. Juan de Cañete, Sugeto que fué muy instruido no solo en la Jurisprudencia, sino en las Matematicas é Historia Civil. La imprimo en el mismo estado en que me la remitió, sin mudarle alguna cosa; solamente añadiré que esta antiguedad se halla en la Jurisdiccion de San Juan de los Llanos. La misma descripcion, aunque menos prolixa, me ha comunicado ahora poco un Sugeto que vivió en aquella Jurisdicción. ¡Que conocimientos utiles acaso se verificaran si algun sugeto curioso é instruido registrase muy por menor esta abandonada Poblacion!.

Me ha parecido coveniente añadirle algunas notas para aclarar ó especificar muchas expresiones de que usó el Licenciado Cañete; porque como son expresiones propias del Pais, serviran de escollo á los lectores que no las han oido.

(e) En el año de 1767 por orden superior se mandaron despedazar dos pilastrones esculpidos con Geroglificos de baxo relieve que estaban en la orilla de la Laguna de Tezcuco, en lo que llaman Pantitlan: no he visto cosa que mas se asemeje á los que describe el Capitan Cooc.

(f) Los Mexicanos para decir aqui, profieren Nican, Sannican, cerca de aqui Amonican, no es aqui. Nican quema, aqui es \&c. ¿Los primeros que desembarcaron en Nootca por señas, porque no pudieron tener interprete, harian algunas preguntas á los habitantes con el fin de saber algo de aquel Pais, y estos responderian Nican ó Nootcan? ¿Viciaron la voz del dialecto usado de aquellas gentes, ó estas varian en el dialecto respecto á los Mexicanos? Las investigaciones que en lo venidero se hagan, aclararán ó desvanecerán esta congetura: lo cierto es que los primeros que abordaron á la Costa de Veracruz preguntaron á los moradores á donde estaba el pais mas abundante de oro, y ellos respondieron Colua, esto es al Poniente, y corrompida la expresion por los Españoles permanece el nombre de Ulua con que es conocida la Fortaleza ó Castillo de Veracruz. 
"En un Rancho que fué de mis antepasados, y llegó hasta mi, quarenta leguas de México hacia el Norte con inclinación al Oriente, hay en sus tierras pastales una poblacion antiquisima de mas de una legua de longitud, y tres cuartos de latitud. Ha treinta años que no voy á ella, me persuado á que exceda de treinta mil casas, unas mayores que otras. No tiene calles en orden; pero claramente se percibe la distincion que tienen unas pertenencias de otras: entre las cuales mediaban unos angostísimos callejoncillos. Hay paredes de dos y tres varas de alto, muy gruesas: Estan hechas sin cal, lodo ni otra mezcla alguna, y si con mucho artificio acuñadas, en-

83.

lazadas y apretadas unas piedras con otras. Hay tambien mucha piedra labrada, y Cues $^{(a)}$ y Adoratorios. Solo una calle hay que atraviesa la población de Oriente á Poniente, y es calzada angosta con pretiles altos por uno y otro. En partes se inclina al Norte, y en partes al Sur, y en algunos parajes tiene gradas para subir y baxar: su pavimento es de piedra como la de recinto ${ }^{(\mathrm{b})}$ muy sólida y lisa, y se conoce que esto último consiste en lo mucho que la traficaron. Se encuentran fragmentos de losa, y algunos utensilios como metates, metlapiles ${ }^{(\mathrm{c})}$ y caxetes; ${ }^{(\mathrm{d})}$ pero todo muy tosco y basto. Oí á mi Padre que en tiempo de mi bisavuela se halló enterrado un Leon de piedra, y que este se colocó en una Capilla, y sobre su cabeza la pileta de agua bendita. Tambien se han encontrado Estatuas de piedra de figura humana; pero muy mal hechas. Todo el distrito y sus contornos es abundante de caza; por lo que llevado yo de mi aficion freqüenté aquellos parages, que en tiempo de lluvias son una delicia por las muchas especies de flores con que se matizan aquellos solares, y antiquísimas paredes. No hay ni las mas miníma noticia ni aún del nombre que tuvo esa Ciudad; pero sí muchos indicios que no refiero por no dilatarme, de que se asoló muchos siglos antes de la Conquista, que fué por la escazés de agua. Todo aquello está ya montuoso y reducido á selvas desde antes que fundase el Rancho mi rebisavuelo, que yá lo encontró muy salbatico y con Encinas, Sabinas y Pinos viejísimos nacidos dentro de las Casas y Solares, y aún hay un Ocote ${ }^{(e)}$ muy alto que nació sobre un $\mathrm{Cu}$, ó Torre. Es mucha la piedra labrada que se ha sacado para esquinas de edificios y enlosados de patios, troxes, \&c. En toda la Poblacion no se encuentra un árbol frutal; pero sí varias especies de yerbas comestibles, y una de

\footnotetext{
(a) Sepulcros.

(b) En México conocen por piedra de recinto á una Laba, ó piedra volcánica.

(c) Metates, Metlapiles con los que se muele el Chocolate: el Metate es una piedra algo concava, y el Metlapile una piedra delgada que termina en dos conos.

(d) Estos son utensilios como cazuelas.

(e) Pino.
} 
frixol muy sabroso que se enreda como la Yedra, y produce una flor muy hermosa. Hay muchos magueyes de los comunes y otros blancos, de penca muy delgada, ancha y alta, que produce una pita muy fina. De esta última especie se saca un excelente pulque de mejor gusto que el común.

Yo hice sacar una mesa de piedra cuya longitud tenia cerca de dos varas, la latitud cosa de tres quartas, y la profundidad como una tercia: los pies eran quatro, de una pieza con la tabla, y de un palmo de altura. No he visto lápida mas bella. El granillo muy fino y semejante al de las piedras de amolar en lo liso, de color blanco con listas ó vetas azules. Estaba dentro de un Solar espacioso de tierra muy pingue y fertil, y por eso muy enyerbado. A pocas varas de distancia encontré con una Estatua de figura humana, como de una vara de alto, muy fea; era de piedra de canteria comun. La cabeza y brazos estaban quebrados y dividos del cuerpo, el que levanté pa-

84.

ra observarlo, y prontamente lo dexé caer por que estaba debaxo de él una horrible Tarantula, lo que me hizo salir con prontitud del paraje en que encontré una Cueva artificial, y allí cerca unas paredes altas que manifestaban haber sido mirador; por lo que me hize juicio de que la habitación fué de algun Magnate, y la Estatua algun Idolo. ${ }^{(\mathrm{f})}$ Piedra como la de la mesa no la hay en todos aquellos contornos, ni yo la he visto jamás en parte alguna: por lo que me persuado á que fué conducida al lugar desde alguna tierra remota para el servicio de algun Príncipe ó persona de autoridad. Mandé hacer una sierra fuerte y de buen temple; y en dos días los Indios Carpinteros de la hacienda dividiendola por el grueso reduxeron á tres losas la que antes fue una sola; las que dandoles con tezontle ${ }^{(\mathrm{g})}$ quedaron muy lisas, y tuve con ellas para el pavimento y costados de una caxa de un Placer.

Mucho mas se me ofrecia que decir; pero mis ocupaciones, y mi edad no me permiten dictar mucho, y solo en conversación podría comunicarme á Vm. muchas cosas que contemplo le gustarian."

Nuestro Señor guarde la vida de Vm. muchos años. México y Octubre 17 de 1786. B.L.M. á Vm. su mas atento y aficionado Servidor Joseph Francisco Ruiz Cañete. -

(f) Pudo ser Estatua que representase á algun hombre de caracter, porque no todas las Estatuas de los Idolátras fueron simulacros, su escultura se extendía á mas de lo que era su falsa creencia.

(g) Pusolana. 


\section{Referencias}

Alcina Franch, José. "Guillermo Dupaix y los orígenes de la arqueología en México."

En Descubrimiento Científico de América, José Alcina Franch, 255-279. Barcelona:

Antropos, 1988 (Autores Textos y Temas Antropología, 16).

. "Guillermo Dupaix y los viajes de exploración arqueológica por la Nueva España."

En Descubrimiento Científico de América, José Alcina Franch, 221-253. Barcelona:

Antropos, 1988 (Autores Textos y Temas Antropología, 16).

. Arqueólogos o Anticuarios, Historia de la arqueología en la América Española. Barcelona:

Ediciones del Serbal,1995 (Libros del Buen Andar).

Alzate, José Antonio. "Sobre el origen de los mexicanos." Gazeta de Literatura, no. 11 (8 de febrero 1790): 81-84.

. "Descripción de Antigüedades de Xochicalco. Dedicada a los Señores de la Actual

Expedición Marítima Alrededor del Orbe." Suplemento de la Gazeta de Literatura, (1791):

1-24. En México por Don Felipe Zuñiga y Ontiveros, 5 láminas.

_. [1790]. "Sobre el origen de los mexicanos." En Gacetas de Literatura de México, por José Antonio Alzate y Ramírez, 280-284. Puebla: Reimpresas en la oficina del hospital de S. Pedro, á cargo del ciudadano Manuel B. Abad, 1831 (tomo I).

_. [1791]. "Descripción de Antigüedades de Xochicalco. Dedicada a los Señores de la Actual Expedición Marítima Alrededor del Orbe." En Suplemento de la Gazeta de Literatura. Gacetas de Literatura de México, por José Antonio Alzate y Ramírez, 1-16. Puebla: Reimpresas en la oficina del hospital de S. Pedro, á cargo del ciudadano Manuel B. Abad, 1831 (tomo II).

. [1790]. "Sobre el origen de los mexicanos." En Memorias de la Sociedad Patriótica de la Habana, por una Comisión Permanente de su Seno, 326-329. Habana: Imprenta del Gobierno y Capitanía General por S.M., 1840 (tomo x).

. Observaciones útiles para el futuro de México, selección de artículos, 1768-1795, recopilación, notas y edición de Miruna Achim. México: ConACulta, 2012 (Cien de México).

_. [1790]. "Sobre el origen de los mexicanos." En Observaciones útiles para el futuro de México, selección de Artículos, 1768-1795, recopilación, notas y edición de Miruna Achim, 410-414. México: ConACulta, 2012 (Cien de México).

—. [1791]. "Descripción de antigüedades de Xochicalco. Dedicada a los señores de la actual expedición marítima alrededor del orbe." En Observaciones útiles para el futuro de México, selección de artículos, 1768-1795, recopilación, notas y edición de Miruna Achim, 415-448. México: ConACulta, 2012 (Cien de México).

Anderson, George William (editor), A New, authentic, and complete collection of voyages round the world, undertaken and performed by royal authority: containing an authentic, entertaining, full, and complete history of Captain Cook's first, second, third and last voyages, undertaken by order of his present Majesty, for making discoveries in geography, navigation, astronomy, \&c. in the southern and northern hemispheres \&c. \&c. \& c.... the whole comprehending a full account, from the earliest period to the present time/now publishing under the immediate direction of George William Anderson, Esq.; assisted by a principal officer who sailed in the Resolution sloop, and by many other gentlemen of the most distinguished naval abilities. London: Printed for the proprietors, and published by Alex Hogg, 1784.

Archaeological Research. Ancient Urbanism at Xochicalco: The Evolution and Organization of Prehispanic Society, editado por Kenneth Hirth. Salt Lake City: The University of Utah Press, 2000 (vol. I, 1 plano).

Archaeological Research. The Xochicalco Mapping Project, editado por Kenneth Hirth.

Salt Lake City: The University of Utah Press, 2000 (vol. II).

Atlas arqueológico de la República Mexicana, formado por el Instituto Nacional de Antropología e Historia de la Secretaría de Educación Pública. México: Instituto Panamericano de Geografía e Historia, s.f. (no. 41, mapas plegables).

Aureliano, Ramón, Ana Buriano y Susana López (coordinadores). Índice de las Gacetas de Literatura de México. México: Instituto Mora, 1996. 
Bernal, Ignacio. "Cien años de arqueología mexicana (1780-1880)." Cuadernos Americanos LXII, nº 2 (marzo-abril 1952): 137-151.

—. Historia de la arqueología en México. México: Porrúa, 1979 (103 láminas). . "Cien años de arqueología mexicana (1780-1880)." Cuadernos Americanos LXII, no. 2 (marzo-abril 1952): 137-151.

"Biografía Mexicana, Don José Antonio Alzate." En El Museo Mexicano ó Miscelánea Pintoresca de Amenidades Curiosas e Instructivas, 8-10. México: Lo imprime y publica Ignacio Cumplido, calle de los Rebeldes casa número 2, 1843 (tomo I).

Cabello Carro, Paz. "La Arqueología Ilustrada en el Nuevo Mundo." En De Pompeya al Nuevo Mundo. La Corona española y la Arqueología en el siglo XVIII, editado por Martín Almagro-Gorbea y Jorge Maier Allende, 255-279. Madrid: Real Academia de la Historia y Patrimonio Nacional-Publicaciones del Gabinete de la Real Academia de la Historia, 2012 (Antiquaria Hispánica, 23).

Carreño, Alberto M. [1913]. "El bachiller don José Mariano Mociño y la expedición científica del s. XVIII." En Noticias de Nutka a través del tiempo, presentación, ensayo y $2^{\mathrm{a}}$ edición de la de Alberto María Carreño por Felipe Echenique March, 37-146. México: INAH, 2013.

Carrera, Estampa Manuel. "Relaciones Geográficas de la Nueva España Siglos XVI y XVIII." Estudios de Historia Novohispana no. 2 (1968): 233-263.

Cortés, Hernán. Historia de la Nueva España, escrita por su esclarecido conquistador Hernán Cortés, aumentada con otros documentos, y notas por el Ilustrissimo Señor Don Francisco Antonio de Lorenzana, Arzobispo de México. México: Con las licencias necesarias en la Imprenta del Superior Gobierno, Br. D. Joseph Antonio de Hogal en la Calle de Tiburcio, 1770.

_. [1770]. Historia de la Nueva España, escrita por su esclarecido conquistador Hernán Cortés, aumentada con otros documentos, y notas por Francisco Antonio de Lorenzana.

México: Miguel Ángel Porrúa-Secretaría de Hacienda y Crédito Público, 1981 (tomos I, II, III, IV, ilustraciones y mapas plegados).

Cortés I., María Eugenia y Francisco Pablo Ramírez G. Rescate de antiguas medidas iberoamericanas, Instituto Mexicano del Petróleo, 1998. Revisado el 31 de enero, 2020 https://www.smf.mx/boletin/Ene-98/articles/medidas.html.

Clavijero, Francisco Javier. [1958]. Historia antigua de México, Mariano Cuevas editor y prólogo, Mapa, México: Porrúa, 1972 (Sepan Cuantos, 29).

. Historia antigua de México, obra escrita en italiano, traducida por Francisco Pablo Vázquez, México: Editorial del Valle de México, 1978.

De Anza, Juan Bautista. "Anza's Diary of the Second Anza Expedition, 1775-1776 (J)." In Anza's California Expeditions. The San Francisco Colony, Diaries of Anza, Font and Eixarch, and Narratives by Palóu and Moraga, translated from the original Spanish manuscripts and edited by Herbert Eugene Bolton, xxi, 1-200. Berkeley: University of California Press, 1930 (vol. III).

Dupaix, Guillermo. Expediciones acerca de los antiguos monumentos de la Nueva España, 1805-1808, edición, introducción y notas de José Alcina Franch. Madrid: Jose Porrúa Turanzas, 1969 (vols. 27-28, Chimalistac, 130 ilustraciones). . Atlas de las Antigüedades mexicanas halladas en el curso de los tres viajes de la real expedición de antigüedades de la Nueva España, emprendidas en 1805, 1806 y 1807. Facsímil de la edición de París, estudio introductorio de Roberto Villaseñor Espinosa, prefacio de Miguel León Portilla. México: San Ángel Ediciones, 1978 (32 láminas de la primera expedición, 134 láminas de la segunda expedición y 48 láminas de la tercera expedición).

Echenique March, Felipe I. Noticias de Nutka a través del tiempo, presentación, ensayo y $2^{\mathrm{a}}$ edición de la de Alberto María Carreño por Felipe Echenique March. México: INAH, 2013. . "Ensayo. José Alzate y Ramírez, impulsor intelectual de José Mariano Moziño y sus noticias del puerto de San Lorenzo de Nutka en la Nueva California." En Noticias de Nutka a tráves del tiempo, presentación, ensayo y $2^{\mathrm{a}}$ edición de la de Alberto María Carreño por Felipe Echenique March, 17-34. México: INAH, 2013. 
Estrada de Gerlero, Elena Isabel. "La Real Expedición Anticuaria de Dupaix." En México en el Mundo de la Colecciones de Arte, 168-181. México: Editorial Azabache, 1994 (Nueva España 2, vol. 4).

—. Guillermo Dupaix, precursor de la historia del arte prehispánico. México: INAH-Secretaría de Cultura-Instituto de Investigaciones Estéticas, UNAM, 2017.

Gacetas de Literatura de México. Por José Antonio Alzate. Puebla: Reimpresas en la oficina del hospital de S. Pedro, á cargo del ciudadano Manuel Buen Abad, 1831 (tomos I-IV).

García Cook, Ángel. "Cantona, Puebla, una gran ciudad prehispánica." Arqueología Mexicana, Edición Especial, no. 73 (abril 2017): 8-82. and Beatriz Leonor Merino Carrión. "Cantona: Urbe prehispánica en el Altiplano Central de México." Latin American Antiquity 9, no. 3 (1998): 191-216. doi.org/10.2307/971728. . "El proyecto arqueológico Cantona." Arqueología, historia y antropología, In memoriam José Luis Lorenzo, coordinado por Jaime Litvak y Lorena Mirambell, 161-203. México: INAH, 2000 (Científica, 415).

García García, Enrique. La plaza oriente de Cantona, Puebla, cultura material y cosmovisión. Tesis en Arqueología, Escuela Nacional de Antropología e Historia, 1999.

Gerhard, Peter. [1972]. Geografía histórica de la Nueva España, 1519-1821. Traducción de Stella Mastrangello, mapas de Reginald Piggott. México: Instituto de Investigaciones Históricas-Instituto de Geografía-UNAM, 1986 (Espacio y Tiempo, 1).

González Claverán, Virginia. La expedición científica de Malaspina en Nueva España 1789-1794. México: Centro de Estudios Históricos del Colegio de México, 1988.

Hirth, Kenneth y Ann Cyphers Guillén. Tiempo y Asentamiento en Xochicalco. México: Instituto de Investigaciones Antropológicas- UNAM, 1988 (Monografías, 1).

Humboldt, Alejandro de. [1822]. Ensayo político sobre el Reino de la Nueva España, estudio preliminar, revisión del texto, cotejo, notas y anexos de Juan A. Ortega y Medina, $7^{\mathrm{a}}$ edición, México: Porrúa, 2014 (Sepan Cuantos, 39).

Kino, Eusebio Francisco. Las Misiones de Sonora y Arizona comprendiendo: La crónica titulada: "Favores Celestiales" y la "Relación Diaria de la Entrada al Noroeste.” Versión paleográfica e índice por Francisco Fernández del Castillo, con noticias bibliográficas del Padre Kino y sus exploraciones y fundaciones por el Dr. Emilio Bose, México: Porrúa, 1989.

León, Nicolás. "Los monumentos arqueológicos de Cantona." Semanario Literario Ilustrado III, no. 127, (1903): 248-250.

—. [Cantona], Records of the Past. Vol. II, (July 1903): part VII, 224.

Litvak, Jaime. "Investigaciones en el Valle de Xochicalco: 1569-1870." Anales de Antropología, 102-124. México: Instituto de Investigaciones Antropológicas-UNAM, 1971 (no. 8).

López Hernández, Haydeé. Los estudios histórico-arqueológicos de Enrique Juan Palacios. México: INAH - Secretaría de Cultura, 2016 (Colección Historia, Serie Sumaria).

López Luján, Leonardo. "El Tajín en el siglo XVIII: Dos exploraciones pioneras en Veracruz." Arqueología Mexicana xv, no. 89 (Enero-febrero 2008): 74-81.

. "El capitán Dupaix y su álbum arqueológico de 1794." Arqueología Mexicana XIX, no. 109, (2011): 71-81.

. El Capitán Guillermo Dupaix y su albúm arqueológico de 1794. Ediciones del Museo Nacional de Antropología. México: INAH, 2015.

_ y Sonia Arlette Pérez. "Las 'correrías particulares' del capitán Guillermo Dupaix." Arqueología Mexicana xIX, no. 119 (2013): 78-89.

Lozoya, Xavier. Plantas y Luces en México, La Real Expedición Científica (1787-1803). Barcelona: Ediciones Serbal, 1984 .

Mapa de las Provincias de Ostimuri, Sinaloa Sonora, y demás circunvezinas y parte de California, Mapoteca Orozco y Berra, SAGARPA, (Varilla OYBBC01, n. de clasificador 266-OYB7221-A).

Márquez, Pietro. Due antichi monumenti di archittetura messicana. Roma: Presso Ill Salomoni, 1804 (4 láminas). 
_. "Monumentos de arquitectura mexicana" [primer monumento], traducidos al español por F[rancisco del] P[aso y] T[roncoso]. Anales del Museo Nacional de México, primera época, tomo II, no. 1 (1882): 283-290 (México: Imprenta de Ignacio Escalante, Bajos de San Agustín).

"Monumentos de arquitectura mexicana ilustrados por el P. Pedro José Márquez" [segundo monumento], traducidos al español por F[rancisco del] P[aso y] T[roncoso], Anales del Museo Nacional de México, primera época, tomo III, no. 1 (1886): 76-86 (México: Imprenta de Ignacio Escalante, Bajos de San Agustín).

Mange, Juan Matheo. Luz de tierra incógnita en la América Septentrional y Diario de las exploraciones en Sonora [1720], versión, notas e índice alfabético por Francisco Fernández del Castillo, México: Talleres Gráficos de la Nación. "Diario Oficial”, 1926 (Publicaciones del Archivo General de la Nación, tomo X).

Mendiola Galván, Francisco. Las texturas del pasado. Una historia del pensamiento arqueológico en Chihuahua, Chihuahua: CONACULTA-INAH-CONACYT, 2008 (INAH-Chihuahua, ENAH-Chihuahua).

Moreno de los Arcos, Roberto. "Las Notas de Alzate a la Historia Antigua de Clavijero." Estudios de Cultura Náhuatl, 10 (1972): 359-392.

. "Las Notas de Alzate a la Historia Antigua de Clavijero (Addenda)." Estudios de Cultura Náhuatl, 12 (1976): 85-120.

. "Un eclesiástico frente al estado Borbón." Índice de las Gacetas de Literatura de México de José Antonio Alzate, coordinado por Ramón Aureliano, Ana Buriano y Susana López, 13-35. México: Instituto Mora, 1996.

. "Efemérides de José Antonio Alzate y Ramírez." Índice de las Gacetas de Literatura de México de José Antonio Alzate, coordinado por Ramón Aureliano, Ana Buriano y Susana López, 37-45. México: Instituto Mora, 1996.

Mociño, José Mariano. [1793]. “Noticias del Nutka." En José Mariano Mociño y sus Noticias del Nutka a través del tiempo, edición, presentación, ensayo y za edición de la de Alberto María Carreño por Felipe I. Echenique March, 147-275, México: ConACUlTA-INAH, 2013.

Navarrete, Carlos. "Encuentro con Frans Blom en el rincón de una vieja biblioteca." En Frans Blom con sus propias palabras: cuadernos ocasionales, 29-47. Tuxtla Gutiérrez: Instituto Chiapaneco de Cultura, Talleres Gráficos del Estado, 1991.

_. Palenque, 1784. El inicio de la aventura arqueológica maya. México: Instituto de Investigaciones Filológicas (Centro de Estudios Mayas)-Instituto de Investigaciones Antropológicas, UNAM, 2000 (Cuaderno 26).

Palacios, Enrique Juan. "Hueyaltépetl," Anales del Museo Nacional de Arqueología, época 4, no. 3 (1922): 179-192.

"Descubrimientos de la ciudad de Hueyaltépetl en los límites de la altiplanicie de México.- por Juan Palacios y Miguel E. Sarmiento del Museo Nacional de Arqueología, Historia y Etnografía." Boletín de la Secretaría de Educación Pública, tomo I, no. 2 (1 de septiembre, 1922): 238-245.

_. [1929-1930]. "Los Estudios Histórico-Arqueológicos, de México. Su desarrollo a través de cuatro siglos." En Los Estudios Histórico-Arqueológicos de Enrique Juan Palacios, estudio introductorio, compilación y selección de textos de Haydeé López Hernández, 95-196, México: INAH-Secretaría de Cultura, 2016 (Colección Historia, Serie Historia).

Palop Martínez, Josefina y Alejandro Cerdá Esteve. "Nuevos documentos sobre las expediciones arqueológicas de Guillermo Dupaix por México. 1805-1808." Revista Española de Antropología Americana 27 (1997): 129-152.

Pascual Soto, Arturo. El Tajín en Busca de la Civilización. México: Investigaciones de Estéticas-UNAM-INAH, 2006.

Paso y Troncoso, Francisco. "Dos Monumentos de la Arquitectura Mexicana, Ilustrados por el P. Pedro José Márquez." Anales del Museo Nacional de México, primera época, tomo II, no. 1 (1882): 280-281 (México, Imprenta de Ignacio Escalante, Bajos de San Agustín).

Saussure M. H. de. “Découverte des Ruines D’une Ancienne Ville Mexicaine, située sur Le Plateau de L'Anahuac [Descubrimiento de las Ruinas de una Antigua Ciudad Mexicana, situada sobre la Altiplanicie de Anáhuac]." Bulletin de la Société de Géographie, Rédigé 
par la Section de Publication ET. MM. Alfred Maury, Secrétaire Général de la Commission Centrale. Quatrième Série-Tome Quinzième, nos. 85 a 90 (Janvier-Juin, 1858): 275-294. (Paris, Chez Arthus -Bertrand, Libraire de la Société de Géographie).

Solano, Francisco de. Antonio de Ulloa y la Nueva España, con dos apéndices descripción geográfica-física de una parte de la Nueva España de Antonio de Ulloa, y su correspondencia privada con el Virrey Don Antonio de Bucareli. México: Instituto de Investigaciones Bibliográficas y Biblioteca Nacional de México, 1987 (Serie Fuentes, 2). . (editor), Cuestionarios para la Formación de las Relaciones Geográficas de Indias Siglos XVI/XIX, preparación de los textos Francisco de Solano y Pilar Ponce. Madrid: Consejo Superior de Investigaciones Científicas, Centro de Estudios Históricos, 1988 (Colección Tierra Nueva e Cielo Nuevo, 25).

. "Don Antonio de Ulloa, Paradigma del Marino Científico de la Ilustración Española." Revista Universidade de Coimbra Xxxv (1989): 333-335.

Tschohl, Peter y Herbert Nickel. Catálogo arqueológico y etnohistórico de Puebla-Tlaxcala, edición preliminar A-C, tomo I. México: Fundación Alemana para la Investigación Científica, 1972.

Tyler, Lyman S. "The myth of the Lake of Copala and Land of Teguayo." Utah, Historical Quarterly XX, no. 4 (October 1952): 313-329.

Ulloa, Antonio. Noticias Americanas: Entretenimientos Phisicos- Históricos, Sobre La América Meridional y Septentrional Oriental. Comparación General De los Territorios, Climas, Producciones en las tres especies, Vegetales, Animales y Minerales: Con Relación Partícular De las Petrificaciones de Cuerpos Marinos de los Indios naturales de aquellos Paises, sus usos y costumbres, y usos: De las Antiguedades: Discurso sobre La Lengua y sobre el Modo en que pasaron los primeros pobladores. Madrid: Imprenta de Don Francisco Manuel Mena, Calle de las Carretas, Dedicatoria al Rey e introducción, sin paginación, 1772.

Villaseñor Espinosa, Roberto. "La Real Expedición de Antigüedades de la Nueva España." En Atlas de las Antigüedades mexicanas halladas en el curso de los tres viajes de la real expedición de antigüedades de la Nueva España, emprendidas en 1805, 1806 y 1807, editado por Dupaix. Facsímil de la edición de París, 32 láminas de la primera expedición, 134 láminas de la segunda expedición y 48 láminas de la tercera expedición, prefacio de Miguel León Portilla, 13-52. México: San Ángel Ediciones, 1978. 